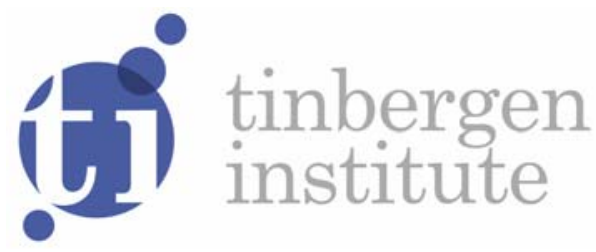

\title{
Understanding the Role of the Public Employment Agency
}

Christian Holzner

Makoto Watanabe ${ }^{2}$

' Ludwig Maximilian University of Munich, Germany;

2 Faculty of Economics and Business Administration, VU University Amsterdam, and Tinbergen Institute, the Netherlands. 
Tinbergen Institute is the graduate school and research institute in economics of Erasmus University Rotterdam, the University of Amsterdam and VU University Amsterdam.

More TI discussion papers can be downloaded at http://www.tinbergen.nl

Tinbergen Institute has two locations:

Tinbergen Institute Amsterdam

Gustav Mahlerplein 117

1082 MS Amsterdam

The Netherlands

Tel.: +31(0)20525 1600

Tinbergen Institute Rotterdam

Burg. Oudlaan 50

3062 PA Rotterdam

The Netherlands

Tel.: +31(0)10 4088900

Fax: +31(0)10 4089031 


\title{
Understanding the Role of the Public Employment Agency*
}

\author{
Christian Holzner ${ }^{\dagger} \quad$ Makoto Watanabe ${ }^{\ddagger}$
}

May 19, 2016

\begin{abstract}
Using a unique vacancy dataset, we find that the Public Employment Agency (PEA) distributes workers more evenly across vacancies than the private market. We investigate the implications of having such a market place by using a directed search model, where firms can search via the PEA or the private market. Lower coordination frictions reduce wage competition and enable registered firms to pay lower wages compared to the private market. This advantage has to be traded off against the negative selection of applicants coming through the PEA. We take these theoretical predictions to the data and find strong support for them.
\end{abstract}

Keywords: Labor Search, Intermediation, Public Employment Agency

JEL: J6

${ }^{*}$ We are grateful to Hermann Gartner, Timo Hener and Andrey Launov for their suggestions regarding the empirical part, and Christopher Flinn and Boyan Javanovic for their comments and suggestions. The survey data used are confidential but not exclusive. Access to the data is provided by the Research Data Centre of the German Federal Employment Agency. For details, see fdz.iab.de. To facilitate replication the Stata do-files are available from the first author upon request.

${ }^{\dagger}$ Ifo Institute for Economic Research at the University of Munich. Address: Poschingerstrasse 5, 81679 Munich, Germany. Email: holzner@ifo.de. Tel.: +49-899224-1278, Fax: +49-899224-1604.

${ }^{\ddagger}$ Department of Economics, FEWEB, VU Amsterdam and Tinbergen Institute. Address: Department of Economics, VU Amsterdam, De Boelelaan 1105, 1081 HV Amsterdam, The Netherlands. Email: makoto.wtnb@gmail.com. Tel.: +31-20598-6030. Fax: +31-20598-9870. 


\section{Introduction}

In most industrialized countries Public Employment Agencies (hereafter, PEA) provide job-broking services - help job seekers to obtain jobs and employers to fill vacancies. The market places provided by PEAs are open to all job seekers and vacancies at zero cost. The existing empirical literature shows that between 35 to 55 percent of all job seekers, including employed workers, and up to 85 percent of unemployed job seekers use the PEA. ${ }^{1}$

Despite the importance of the PEA as a search channel very little is known about its impact on the labor market. We start from the observation that the essential role of the PEA is to alleviate coordination frictions, i.e., the friction that some vacancies might receive many applications while others receive none. We then build a directed search model where firms can decide whether to search via the PEA or the private market. Several implications regarding the application/search behaviors of workers and market outcomes, e.g. the wage and the factors influencing the decision to use a certain search channel, are obtained. These implications are eventually tested with our dataset. The results strongly support our theory.

Before proceeding to the details, it is worth emphasizing that our approach takes seriously the role of the PEA to serve as a coordination mechanism that are related to the frictions present in the job seekers' application process. This is a neglected aspect in the existing literature (see below) that we believe should receive more attention. Providing a platform clearly helps to reduce search costs for both sides of the market. But does it require so much (human) resources ${ }^{2}$ just to run such a platform? The fact that the staff at the PEA can observe and guide the application behavior of their unemployed job seekers and direct it towards vacancies, helps to spread applications more evenly among all registered vacancies. This process requires the centralization and coordination that only intermediaries are able to pursue but individual private firms are not. Whatever new technologies firms develop and whatever efforts they make for strengthening their own recruiting team, they are not able to coordinate the application behavior of job seekers.

For our empirical analysis, we use the German Job Vacancy Survey, a representative establishment dataset collected by the Federal Employment Agency in Germany. This is a perfect dataset for our purpose since it contains numerous questions regarding the recruitment process. Most importantly we know how many applicants and how many suitable applicants a registered firm received from the PEA and through other search channels.

We show that job- and firm-characteristics, which matter for the number of applicants attracted through the private market, play no role in explaining the number of applicants sent by the PEA. This

\footnotetext{
${ }^{1}$ See Holzer (1988) and Blau and Robins (1990) for the US, Osberg (1993) for Canada, Gregg and Wadsworth (1996) for the UK, Addison and Portugal (2002) for Portugal, and Weber and Mahringer (2002) for Austria. The evidence on the fraction of registered vacancies is scarce. Pollard et al. (2012) report in a survey for the Department of Work and Pensions that in the Unitied Kingdom 39 percent of all establishments used the Jobcentre Plus in 2011. We find that in the years 2005 to 2008 around $48.3 \%$ of all vacancies in Germany registered with the PEA.

${ }^{2}$ The government expenditure on administration of the PEA in 2012 was $0.3 \%$ of GDP (8.9 billion EUR) in Germany. The corresponding figures are $0.04 \%$ (6 billion USD) in USA and $0.05 \%$ (250 billion JPY) in Japan.
} 
indicates that the PEA distributes its job seekers irrespective of these characteristics. By doing so it helps less attractive vacancies to increase their number of applicants. In addition we find that the (residual) variance of the number of applicants sent by the PEA is significantly lower compared to the (residual) variance of the number of applicants received through the private market. This shows that the PEA distributes applicants more evenly among vacancies. Both findings support the hypothesis that the PEA alleviates coordination frictions.

To rationalize our empirical findings we construct a theoretical model using a directed search approach. In our setup, all unemployed are registered at the PEA. For them, searching in the decentralized market is costly. Firms can choose between two alternative methods of finding a worker: the decentralized (or private) market and the PEA. We show that some or all of the firms will choose to use the search market in equilibrium. The equilibrium wage offered by firms in the search market is higher than the one offered by firms registered with the PEA. This occurs because registered vacancies do not need to compete with each other since the coordination mechanism used by the PEA assigns unemployed to vacancies irrespective of the posted wage. In contrast, the decentralized mechanism of directed search market requires that vacancies offer a higher wage to attract workers. Given this differential allocation mechanisms, job seekers are only willing to be engaged in costly search for a better-paid job if they can expect a high enough chance of being suitable to the position. This gives rise to market segmentation where the proportion of suitable workers is higher in the search market than in the PEA.

We then empirically test of our theory. First, we show that the fraction of suitable applicants at vacancies registered with the PEA is about 10 percent lower than at vacancies that only use decentralized search channels. ${ }^{3}$ We also show that those workers, who are eventually hired, are regarded as equally qualified and experienced irrespective of whether they are hired through the PEA or the private market. This is in line with our theory and suggests that firms rather risk to go without a worker than employing a worker, who does not meet the standards.

Second, we investigate how the PEA affects wages by looking at two pieces of information. First of all, registered firms pay 4 to 5 percent lower wages than unregistered firms. This wage difference persists after controlling for many observable worker-, firm-, and job-characteristics, including the previous employment status of the hired worker. Also, firms registered with the PEA are more likely to report difficulties in the recruitment process, because their applicants demanded higher wages. This not only supports the direct evidence above that registered vacancies offer lower wages than unregistered vacancies, but also implies that one and the same worker can receive multiple wage offers, which differ systematically depending on whether the vacancy is registered with the PEA or not.

Third, our theory suggests that a higher expected number of applicants and a higher fraction

\footnotetext{
${ }^{3}$ This evidence is complementary to the evidence provided in the existing literature, which shows that less suited workers are more likely to use the PEA. Our complement is important to understand the role of the PEA in the labor market, since the evidence from the workers' side alone does not necessarily imply that registered vacancies receive on average a less suited pool of applicants. It could have been that the PEA has an informational advantage and sorts out less suited workers and thereby helps registered firms to overcome information asymmetries. Instead, our empirical result suggests that this is not the case.
} 
of suitable applicants coming from the PEA (coming from the private market) increase (decrease) the probability to register a vacancy with the PEA. Including the respective predicted values from regressions on the number of applicants and suitable applicants into the probit regression, which explains the use of the PEA as search channel, turns out to be affirmative.

Finally, our analysis also enables us to suggest a reason why not all vacancies register with the PEA despite its service being free of charge. This is even more puzzling than it sounds once we take into account the fact that the PEA enables firms to pay lower wages, and that advances in information technology make it possible for the PEA to centralize job applications and to mitigate coordination frictions. Given our evidence, we believe that such a behavior is driven by the implicit cost associated with the less suited pool of applicants. Our story therefore helps us to better understand the functioning of the labor market in the presence of the PEA.

The sequel of the paper is organized as follows. This introductory section closes with the literature survey. Section 2 describes how the PEA works in Germany. Section 3 uses data from the German Job Vacancy Survey to show which factors determine the use of the PEA as search channel, and that the PEA reduces coordination frictions. Section 4 presents the theoretical model of the labor market in the presence of the PEA. Section 5 investigates the empirical implications of the theory and shows that registered vacancies pay lower wages, and that the applicants sent by the PEA are on average less suited. Section 6 concludes. All proofs and some omitted tables are collected in the Appendix.

Related Literature The existing literature studies the use of the PEA and the effects of using the PEA from the job seekers' perspective. It shows that unemployment benefit recipients, low skilled workers, long-term unemployed and workers with few job opportunities are more likely to use a PEA. ${ }^{4}$ The empirical evidence for the effect on wages is mixed. Holzer (1988) reports for the US and Addison and Protugal (2002) for Portugal that workers, who searched through the PEA, received lower wage offers (after controlling for worker characteristics). Osberg (1993) finds for Canada and Weber and Mahringer (2002) for Austria that the wage difference disappears after controlling for worker characteristics. Our result suggests that wages paid by registered vacancies are indeed significantly lower than the wages paid by unregistered vacancies. If worker-, firm-, and job- characteristics are not sufficient to account for the gap, then our analysis suggests, that the coordination mechanism in the PEA could be responsible for why some studies obtain a wage gap even after controlling for observable characteristics.

The pioneering theoretical work of the PEA is developed by Pissarides (1979) who uses a random search approach. We adopt the baseline setups in accordance with his model as much as possible. Like him we assume that all unemployed are registered at the PEA, that searching in the decentralized market is costly for workers, and that firms can choose between two alternative methods of finding a worker: the search market and the PEA. There are two major differences between his and our model. First, workers are homogeneous in Pissarides (1979), while the key ingredient of our model is that

\footnotetext{
${ }^{4}$ See Holzer (1988) and Blau and Robins (1990) for the US, Osberg (1993) for Canada and Gregg and Wadsworth (1996) for the UK.
} 
workers differ in expected suitability for the job. Second, Pissarides (1979) assumes an exogenous and identical wage in both markets. In contrast, we show that firms in the decentralized market choose to post higher wages than firms registered with the PEA. Since the value of searching in the private market is higher for workers with a high expected suitability, the endogenous wage differential allows firms in the private market to attract a better pool of applicants. In an extension, Pissarides (1979) considers the limiting case where search frictions are eliminated in the PEA. He finds that in this case the private market collapses and all workers search via the PEA. This is in contrast to our model. We show that the positive selection of workers in the search market ensures the existence of the decentralized search market even if the PEA manages to match the short side of the market.

Our model is related to the literature of intermediation. Watanabe $(2010,2013)$ provide a directed search model of middlemen (e.g., retailers, wholesalers, trading entrepreneurs, dealers or brokers of services and durable goods and assets). ${ }^{5}$ He demonstrates that backed by the capability of dealing with many agents at a time, middlemen find it optimal to provide customers with proximity or a lower likelihood of experiencing stockout, charging a higher price. That the PEA in the present framework provides a coordinated transaction is similar to his middlemen's capability of pursuing large-scaled dealings - our directed search approach well captures the intermediary's role to mitigate coordination frictions. In contrast to the literature, however, the PEA does not act as a private agent, who charges a premium for their service. This raises the question why not all agents use the middlemen. In a recent progress, Gautier, Hu and Watanabe (2015) offer a hybrid model of middlemen and marketmakers (i.e., platform), and study the choice of the two alternative intermediation modes. Unlike in the present model, agents are homogeneous and the issue of differential composition of heterogeneous agents is not addressed.

In the directed search literature, where workers simultaneously apply for multiple jobs, Albrecht, Gautier and Vroman (2006) show that firms engage in Bertrand competition, if their applicant receives two or more offers. ${ }^{6}$ Unlike in their setup, we assume wage commitment and show that a low wage can survive in equilibrium due to the coordinated allocation mechanism used by the PEA. Galenianos and Kircher (2009) consider the case of commitment with homogeneous workers and show the existence of an equilibrium wage dispersion. In our model, there are some workers, who use both the search market and the PEA and hence receive multiple offers - one from the search market and the other from

\footnotetext{
${ }^{5}$ The seminal work in the literature of middlemen is Rubinstein and Wolinsky (1987). While most of the models in the literature would be viewed as describing general markets, there are some models (e.g., Yavas, 1994, Masters, 2007, Watanabe, 2010) that feature labor market intermediation or turnover behaviors. See Watanabe (2013) for the references of the recent contributions.

${ }^{6}$ In the competing auctions literature by e.g. McAfee (1993), Peters and Severinov (1997), Albrecht, Gautier, and Vroman $(2012,2014)$ sellers use auctions to direct buyers with private information. With private information and single application of workers, Menzio (2007) considers wage-bargaining in a framework where firms use cheap talk to signal private information about the quality of a vacancy. Delacroix and Shi (2013) consider a directed search model with signaling, where sellers can distort their posted prices upward in order to signal high quality. Michelacci and Suarez (2006) analyze under which conditions firms prefer wage posting over wage bargaining. Guerrieri, Shimer, and Wright (2010) consider an environment where firms can post complete contracts and who establish that firms can always use these contracts to separate types.
} 
the PEA. In this setup we show that, while the search market has a unique wage, a wage differential exists between the search market and the PEA. Our modeling choice reflects the institutional difference between the two market places in reality.

There are very few other papers that consider the role of the PEA. Fugère et al. (2009) uses a structural partial search equilibrium model to investigate the hypothesis by Pissarides (1979) that a more efficient PEA crowds out private search effort. They consider exogenous, search-channel-specific wage-offer distributions and allow for an endogenous search intensity of workers. Using French data to structurally estimate the model they find that the exit rate from unemployment increases with the arrival rate of job contacts obtained by the PEA. This is especially the case for low-skilled workers. Launov and Wälde (2014) use a structural model to analyze to which extend an increase in operating efficiency of the PEA on the one hand and a reduction of unemployment benefits on the other are responsible for the decline in unemployment in Germany from $11.7 \%$ in 2005 to $7.8 \%$ in 2008.

Casella and Hanaki (2008) and Galenianos (2013) study firms' use of referrals by their own employees in addition to formal hiring channels. ${ }^{7}$ Referred workers may be more suited for the job, because referred workers carry a more accurate productivity signal than workers contacted through a formal search channel. The search channels in our model do not differ in their signaling ability. They differ in the allocation mechanism used. In the search market firms can increase the probability to meet a worker by offering a higher wage, while firms' meeting probability at the PEA is independent of the wages they offer. The novelty of our paper is to show that the higher degree of wage competition among firms in the search market compared to the PEA leads to a positive selection of applicants.

\section{How does the Public Employment Agency work?}

In 2015 the PEA in Germany had an overall budget of 31.5 Billion Euros. Around one fourth of the total budget, i.e., 7.93 Billion Euros, was spent on administration including the wage costs for the roughly 90,000 workers employed at the PEA. The German government therefore spends around $0.3 \%$ of German GDP on the administration cost of the PEA. A significant fraction of employees deal with the administration of unemployment benefits. Still, more than half of the the PEA's employees work in the intermediation to help workers and vacancies to find a good match. In this section we explain, what kind of intermediation services are provided by the PEA.

The PEA provides an online search platform (https://jobboerse.arbeitsagentur.de), where job seekers can upload their curriculum vitae, post job wanted adds, and search actively for vacancies posted. Equivalently, firms can post their vacancies and search actively for registered workers. All unemployed workers, who receive benefits, are required to register. The platform can also be used by job seekers, who are not registered as unemployed. For vacancies registration is voluntary. The platform of the PEA cooperates with many private websites doing similar things and both workers and firms can decide

\footnotetext{
${ }^{7}$ Galenianos (2014) models the use of referrals by expanding firms in order to explain inter-industry variation in aggregate matching efficiency.
} 
whether their information is forwarded to the private websites as well. Providing a platform clearly helps to reduce search costs for both sides of the market. But it does not require a lot of human resources to run such a platform. Indeed the same service can be provided by private platforms in the same way. So what additional intermediation service is provided by the staff of the PEA?

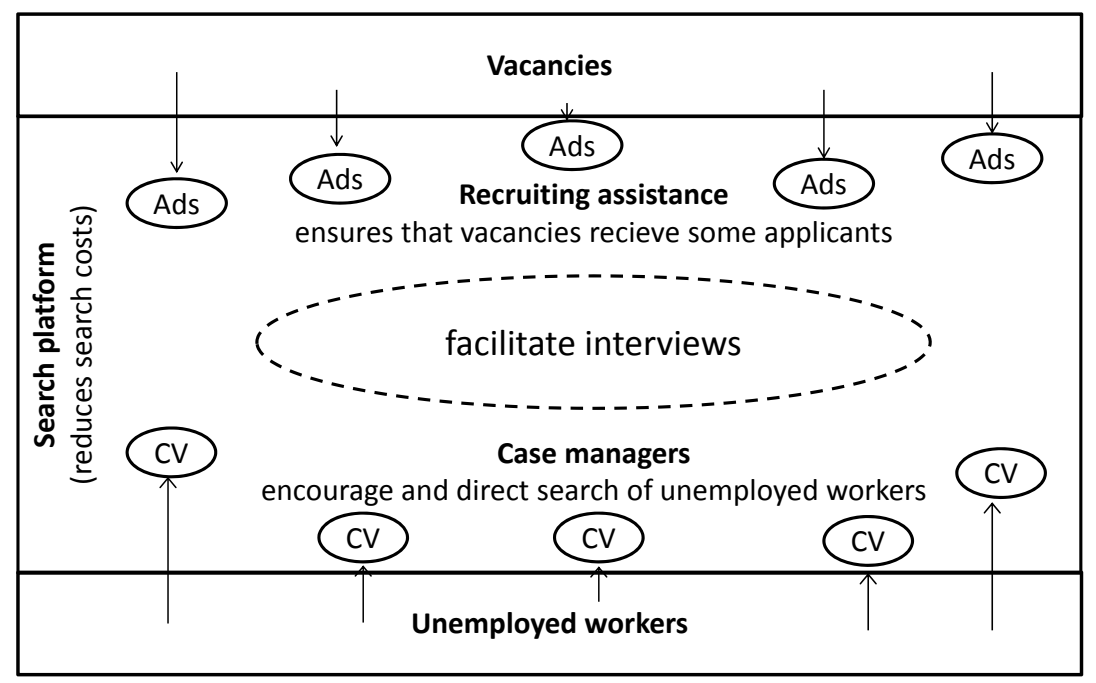

Figure 1: Services provided by the PEA

We summarize the services provided by the PEA in Figure 1. If a worker becomes unemployed, she registers with the PEA and is assigned to a case manager. The case manager will interview the person. A worker, who has some deficits, will be offered training. The majority of unemployed do not get training, they are only taught how to use the platform. The assigned case managers will also determine the search effort appropriate for the worker, and the unemployed worker is required to sign an agreement, which lays down the search requirements. The case manager has access to an individual worker's platform account and can observe where the worker applied and whether the worker has been invited for a job interview. The case manager will propose certain jobs to the worker, if the worker's qualifications match the job description. If the worker does not apply to those jobs, she might be sanctioned. ${ }^{8}$ With their experience case managers can encourage search, broaden the view of applicants, and suggest jobs, which workers would not have considered on their own.

On top of coaching unemployed workers, the PEA offers recruiting assistance to vacancies. Firms which post a vacancy on the platform can decide whether to make the vacancy available for recommendations by case managers. They can also ask their contact person at the PEA to propose workers. They can then contact these workers via the internal mailing system provided by the platform. The contact person is asked to recommend at least one worker within 48 hour. The vacancy can also set a maximum for the number of applicants it wants to receive from the PEA (in order to limit screening costs). In

\footnotetext{
${ }^{8}$ The worker can also apply for jobs not posted on the platform and show the case manager the respective evidence for the exerted search effort.
} 
case the vacancy asks for recruiting assistance the contact person can view the platform account of the specific vacancy and manage the number of recommendations made by case managers accordingly. The contact person can also provide additional information about other services (e.g. subsidies) provided by the PEA. This type of recruiting assistance does not only lower recruitment costs, but also enables firms to minimize the risk of not receiving any applicant.

To summarize, the platform offered by the PEA reduces search costs for job seekers and vacancies. More importantly, its intermediation services reduce coordination frictions, i.e., the friction that some vacancies might receive many applications while others receive none. The fact that the staff at the PEA can observe and guide the application behavior of their unemployed job seekers and direct it towards vacancies helps to spread applications more evenly among all registered vacancies. This will be the hypothesis, which we will test in the next section.

\section{Empirical Analysis}

\subsection{German Job Vacancy Survey}

We use the German Job Vacancy Survey, a dataset collected by the Federal Employment Agency in German. The German Job Vacancy Survey is based on a representative sample of establishments, which is newly sampled each year. The yearly survey started in 1989 and was initially conducted to provide an estimate of the total number of vacancies in Germany relative to the number of vacancies registered with the PEA.

The survey includes establishment level data on the number of employees, number of vacancies, hires and quits in the last 12 months, and information on the industry and region of the firm. The economic conditions of a firm can be proxied by binary indicator variables for "low sales", "financial constraints", and "not enough suitable employees". It also contains a number of questions concerning the last case of a successfully filled vacancy. In this part of the survey firms were asked to provide information on the number of applicants, the number of suitable applicants, the qualification and experience level required for the job, information on job characteristics like occupation, permanent/temporary, full/part-time, and weekend-work and on whether the vacancies were registered with the PEA. The data also contains information on whether a firm experienced difficulties in the recruitment process due to "high wage demands" of applicants, which we use to investigate the existence of a wage difference between registered and unregistered vacancies. Data on wages paid to newly hired workers is only available for the year 2014. We also have some information on the newly hired worker like the age, gender, the previous employment status and whether the hired worker's qualification and experience level was above or below the expected level.

For our main analysis on whether the PEA reduces coordination frictions we can use the information on the number of applicants and the number of suitable applicants in total and the number of applicants 
and the number of suitable applicants sent by the PEA. ${ }^{9}$ This information is available for registered vacancies in the years 2005 to 2008 . We can therefore compare the distribution of (suitable) applicants sent by the PEA and the distribution of (suitable) applicants coming through the private market for one and the same vacancy. That is, we can control for vacancy fixed effects.

\subsection{Who registers with and hires through the PEA?}

In the years 2005 to $2008,55.7 \%$ of all vacancies in Germany were advertised in news papers, $48.3 \%$ used the services provided by the PEA (12.6\% only at the agency, $12.7 \%$ only on the PEA-online platform and $23.0 \%$ both), and $45.3 \%$ of all vacancies were posted on the internet (excluding the online-platform of the PEA). The PEA is thus the second most used search channel to contact workers. Registered firms used on average three different search channels (3.1), unregistered firms on average two different search channels (1.9). We start with investigating which types of firms register which type of vacancy with the PEA. We denote those vacancies as registered which use the PEA search channel (among other search channels).

The use of the PEA as a search channel is almost evenly distributed across all firm sizes. Only small firms with less than 20 employees, which register around $53.1 \%$ of their vacancies, are more likely and large firms with more than 500 employees are less likely to use the PEA as a search channel (43.8\%). Also the fraction of small (large) firms that hire their worker through the PEA is with $22.7 \%(9.6 \%)$ substantially higher (smaller). The use of the PEA as a search channel also differs across vacancy characteristics. Jobs, which require no formal or very low qualifications, are with $60.9 \%$ more likely to be registered with the PEA than jobs, which require a medium (50.3\%) or a high qualification (31.9\%). The fraction of registered jobs requiring occupation specific training (47.8\%) or weekend-work (50.6\%) and the fractions of full-time $(48.2 \%)$ and permanent $(46.3 \%)$ jobs that are registered with the PEA do not differ much from the average. Table 9 in the Appendix shows all summary statistics.

Without having any prior on the effectiveness of a search channel one would expect that one-third of the $48.3 \%$ registered firms hire a worker through the PEA (given that registered firms use on average three search channels). The fraction of firms that contacted the person, which they hired, through the PEA is with $17.3 \%$ slightly higher than one-third of $48.3 \%$. This "effectiveness" differs with job characteristics. The effectiveness is above average for jobs requiring a medium qualification (with a hiring rate of $20.7 \%$ for a registration rate of $50.3 \%$ ) and jobs at firms with less than 20 employees (with a hiring rate of $22.7 \%$ for a registration rate of $53.1 \%$ ). For jobs requiring high qualifications and

\footnotetext{
${ }^{9} \mathrm{~A}$ firm will only label a worker as being "sent by the PEA", if it got notice that the PEA was involved. This is clearly the case, if the vacancy asked for recruiting assistance and was recommended the applicants by its contact person. The firm could also learn it from the applicant. In Germany, it is common practice that one states in the first sentence of the application letter, where one learned about the open position. If the vacancy is registered with the PEA, the firm signals that it is willing to employ unemployed workers. There is therefore no incentive for job seekers to conceal that they learned about the open position through the PEA. In this case the worker could have found the vacancy via the online-platform of the PEA, or her case manager recommended the vacancy to her. For data security reasons the dataset cannot be linked to the information on the online platform. So we cannot observe which kind of intermediation services provided by the PEA were used during the recruitment process.
} 
jobs in firms with more than 500 employees the hiring rate is with $5.7 \%$ and $9.6 \%$ substantially lower than what one would have expected according to the respective $31.9 \%$ and $43.8 \%$ registration rate.

In Table 1 we show which firm and vacancy characteristics are associated with using the PEA as search or hiring channel. Table 1 presents marginal effects based on multivariate probit regressions. One would expect that those firm and vacancy characteristics, which are highly correlated with a successful hiring through the PEA, to be also highly correlated with the use of the PEA as a search channel. This is true for permanent jobs and jobs at large firms. Both factors are negatively correlated with the use of the PEA as hiring and search channel. Firms that are financially constrained are more likely to use the PEA as search as well as hiring channel.

In columns (3) and (4) of Table 1 we present the correlations between job and firm characteristics and PEA use as a search and hiring channel for a subsample, which only includes vacancies that

Table 1: PEA used as search and hiring channel

\begin{tabular}{|c|c|c|c|c|}
\hline & \multirow{2}{*}{\multicolumn{2}{|c|}{$\begin{array}{l}\text { Probit Regress } \\
\text { full sample }\end{array}$}} & \multicolumn{2}{|c|}{ Marginal Effects } \\
\hline & & & \multicolumn{2}{|c|}{ restricted sample } \\
\hline & \multicolumn{2}{|c|}{ PEA used as } & \multicolumn{2}{|c|}{ PEA used as } \\
\hline & $\begin{array}{c}\text { search channel } \\
\text { (1) }\end{array}$ & $\begin{array}{l}\text { hiring channel } \\
\text { (2) }\end{array}$ & $\begin{array}{c}\text { search channel } \\
\text { (3) }\end{array}$ & $\begin{array}{c}\text { hiring channel } \\
\text { (4) }\end{array}$ \\
\hline number of search channels & & $\begin{array}{c}-0.3690 * * * \\
(0.0119)\end{array}$ & & $\begin{array}{c}-0.4016^{* * *} \\
(0.0167)\end{array}$ \\
\hline number of search channels ${ }^{2}$ & & $\begin{array}{c}0.0345^{* * *} \\
(0.0017)\end{array}$ & & $\begin{array}{c}0.0388^{* * *} \\
(0.0024)\end{array}$ \\
\hline low qualification & $\begin{array}{l}0.0334^{*} \\
(0.0177)\end{array}$ & $\begin{array}{c}0.0092 \\
(0.0228)\end{array}$ & $\begin{array}{c}0.0214 \\
(0.0229)\end{array}$ & $\begin{array}{l}0.0187 \\
(0.0307)\end{array}$ \\
\hline high qualification & $\begin{array}{c}-0.0470^{* * *} \\
(0.0151)\end{array}$ & $\begin{array}{c}-0.0439 * * \\
(0.0212)\end{array}$ & $\begin{array}{c}-0.0516^{* * *} \\
(0.0188)\end{array}$ & $\begin{array}{c}0.0112 \\
(0.0261)\end{array}$ \\
\hline occupation specific experience & $\begin{array}{c}0.0123 \\
(0.0088)\end{array}$ & $\begin{array}{c}-0.0139 \\
(0.0114)\end{array}$ & $\begin{array}{c}0.0081 \\
(0.0111)\end{array}$ & $\begin{array}{c}-0.0265^{*} \\
(0.0146)\end{array}$ \\
\hline permanent & $\begin{array}{c}-0.0288 * * * \\
(0.0091)\end{array}$ & $\begin{array}{c}-0.0608 * * * \\
(0.0117)\end{array}$ & $\begin{array}{c}-0.0298^{* *} \\
(0.0116)\end{array}$ & $\begin{array}{c}-0.0668^{* * *} * \\
(0.0155)\end{array}$ \\
\hline full-time & $\begin{array}{c}0.0437 * * * \\
(0.0121)\end{array}$ & $\begin{array}{l}0.0037 \\
(0.0155)\end{array}$ & $\begin{array}{c}0.0373^{* *} \\
(0.0147)\end{array}$ & $\begin{array}{l}-0.0033 \\
(0.0189)\end{array}$ \\
\hline weekend-work & $\begin{array}{l}-0.0151 \\
(0.0142)\end{array}$ & $\begin{array}{c}-0.0330^{*} \\
(0.0184)\end{array}$ & $\begin{array}{c}-0.0364^{* *} \\
(0.0178)\end{array}$ & $\begin{array}{l}-0.0212 \\
(0.0231)\end{array}$ \\
\hline firm size (log) & $\begin{array}{c}-0.0138 * * * \\
(0.0032)\end{array}$ & $\begin{array}{c}-0.0109 * * \\
(0.0042)\end{array}$ & $\begin{array}{c}-0.0099 * * \\
(0.0040)\end{array}$ & $\begin{array}{c}-0.0133^{* *} \\
(0.0053)\end{array}$ \\
\hline "financial constraints" & $\begin{array}{c}0.0536 * * * \\
(0.0158)\end{array}$ & $\begin{array}{c}0.0622^{* * *} \\
(0.0187)\end{array}$ & $\begin{array}{c}0.0587^{* * *} * \\
(0.0201)\end{array}$ & $\begin{array}{l}0.0427^{*} \\
(0.0238)\end{array}$ \\
\hline "low sales" & $\begin{array}{c}0.0227^{*} \\
(0.0128)\end{array}$ & $\begin{array}{c}0.0098 \\
(0.0155)\end{array}$ & $\begin{array}{c}0.0188 \\
(0.0165)\end{array}$ & $\begin{array}{c}0.0294 \\
(0.0208)\end{array}$ \\
\hline "not enough suitable employees" & $\begin{array}{c}0.1564^{* * *} \\
(0.0153)\end{array}$ & $\begin{array}{c}0.0200 \\
(0.0184)\end{array}$ & $\begin{array}{c}0.1352^{* * *} \\
(0.0222)\end{array}$ & $\begin{array}{c}-0.0545^{* *} \\
(0.0270)\end{array}$ \\
\hline \multirow{2}{*}{$\begin{array}{l}\text { year-, region-, occup.-, ind.-FE } \\
\text { (year x region)-FE }\end{array}$} & yes & yes & yes & yes \\
\hline & yes & yes & yes & yes \\
\hline Peudo- $R^{2}$ & 0.0706 & 0.2610 & 0.0748 & 0.3291 \\
\hline $\mathrm{N}$ & 13,116 & 5,883 & 8,134 & 3,329 \\
\hline
\end{tabular}

Source: German Job Vacancy Survey 2005-2008.

Robust standard errors in brackets. ${ }^{* * *}$ indicates $p<0.01 ; * * p<0.05$; $^{*} p<0.1$. 
were successful in filling their vacancy before the intended starting data of the employment contract. Comparing columns (3) and (4) with the results of the full sample in columns (1) and (2) is reassuring. It shows that there is no systematic difference between vacancies that are successful within the expected search period and vacancies that need longer to find an applicant.

\subsection{Does the PEA reduce coordination frictions?}

The aim of the PEA is to reduce coordination frictions in the labor market. To evaluate whether the PEA is able to achieve this goal, we investigate how the PEA distributes job applicants among registered vacancies and compare it to the distribution of job applicants coming from the private market. To control for vacancy fixed effects, we use the information on the number of applicants that a registered vacancy received from the PEA and from the private market. The German Job Vacancy Survey provides this information for the years 2005 to 2008. We only include registered vacancies, which are active in the PEA and the private market. On average a registered vacancy received 20.6 applications, 7.2 of those were sent by the PEA and 13.4 came through other search channels.

\section{Differences in the number of applicants from the PEA and the private market}

We start with comparing the factors that explain the number of applications that a registered vacancy received through the PEA and the private market. These are shown in Table 2, which presents OLS regressions on the (log) number of applicants sent by the PEA in columns (1) and (3) and the (log) number of applications received by the same vacancies through the private market in columns (2) and (4). Columns (1) and (2) present the results for the full sample. Columns (3) and (4) present the results for the restricted sample, which only includes vacancies that were successful in finding an applicant before the initial starting date of the employment contract. The restricted sample is most likely not to suffer from reverse causality, i.e., that firms, which were unsuccessful in attracting applicants until the intended starting date, decide to register their vacancy with the PEA later in the hiring process. The results for the restricted sample are therefore more reliable.

The first observation is that job and firm characteristics seem to matter a lot in the private market but not in the PEA. This can also be seen by looking at the $\mathrm{R}^{2}$, which is between 28.7 to 33.3 for the private market but only 18.8 to 22.0 in the PEA. While jobs requiring low qualifications receive less applicants from the private market, no such effect can be found for applicants sent by the PEA. A similar phenomena can be observed if the job requires high qualification, occupation specific experience, weekend-work, is a permanent job or is posted by a large firm. All these factors are positively correlated with the number of applicants coming through the private market, but the respective coefficients for the number of applicants sent by the PEA are either insignificant or have the opposite sign. ${ }^{10}$ The cases, where job or firm characteristics are insignificant in explaining the number of applicants sent

\footnotetext{
${ }^{10}$ Only full-time jobs receive more applicants from the PEA than from the private market.
} 
Table 2: Number of applicants through the PEA and the private market

\begin{tabular}{|c|c|c|c|c|}
\hline & \multicolumn{4}{|c|}{ OLS-Regressions } \\
\hline & \multicolumn{2}{|c|}{ full sample } & \multicolumn{2}{|c|}{ restricted sample } \\
\hline & \multicolumn{2}{|c|}{ Number of applicants (log) through } & \multicolumn{2}{|c|}{ Number of applicants (log) through } \\
\hline & PEA & private market & PEA & private market \\
\hline & $(1)$ & $(2)$ & (3) & $(4)$ \\
\hline low qualification & $\begin{array}{l}-0.0165 \\
(0.0625)\end{array}$ & $\begin{array}{c}-0.3784^{* * *} \\
(0.0772)\end{array}$ & $\begin{array}{l}-0.1230 \\
(0.0873)\end{array}$ & $\begin{array}{c}-0.4048^{* * *} \\
(0.1091)\end{array}$ \\
\hline high qualification & $\begin{array}{c}-0.1554^{* * *} \\
(0.0600)\end{array}$ & $\begin{array}{c}0.3271 * * * \\
(0.0773)\end{array}$ & $\begin{array}{l}-0.1177 \\
(0.0790)\end{array}$ & $\begin{array}{c}0.2673^{* *} \\
(0.1048)\end{array}$ \\
\hline occupation specific experience & $\begin{array}{c}0.0107 \\
(0.0322)\end{array}$ & $\begin{array}{c}0.1207^{* * *} * \\
(0.0410)\end{array}$ & $\begin{array}{c}0.0350 \\
(0.0434)\end{array}$ & $\begin{array}{c}0.1567^{* * *} * \\
(0.0578)\end{array}$ \\
\hline permanent & $\begin{array}{c}0.0416 \\
(0.0332)\end{array}$ & $\begin{array}{c}0.3073^{* * *} \\
(0.0421)\end{array}$ & $\begin{array}{c}0.0650 \\
(0.0465)\end{array}$ & $\begin{array}{c}0.3561 * * * \\
(0.0607)\end{array}$ \\
\hline full-time & $\begin{array}{c}0.1367 * * * \\
(0.0437)\end{array}$ & $\begin{array}{c}0.0739 \\
(0.0593)\end{array}$ & $\begin{array}{c}0.1177^{* *} \\
(0.0562)\end{array}$ & $\begin{array}{c}0.0322 \\
(0.0782)\end{array}$ \\
\hline weekend-work & $\begin{array}{c}0.0144 \\
(0.0504)\end{array}$ & $\begin{array}{c}0.1518^{* *} \\
(0.0658)\end{array}$ & $\begin{array}{c}0.0375 \\
(0.0704)\end{array}$ & $\begin{array}{c}0.2244^{* *} \\
(0.0911)\end{array}$ \\
\hline firm size (log) & $\begin{array}{c}-0.0303^{* * *} \\
(0.0117)\end{array}$ & $\begin{array}{c}0.1482^{* * *} \\
(0.0151)\end{array}$ & $\begin{array}{l}-0.0080 \\
(0.0157)\end{array}$ & $\begin{array}{c}0.1301^{* * *} \\
(0.0213)\end{array}$ \\
\hline "financial constraints" & $\begin{array}{l}0.0897^{*} \\
(0.0526)\end{array}$ & $\begin{array}{c}0.0014 \\
(0.0673)\end{array}$ & $\begin{array}{c}0.0732 \\
(0.0719)\end{array}$ & $\begin{array}{c}0.0176 \\
(0.0964)\end{array}$ \\
\hline "low sales" & $\begin{array}{c}0.0098 \\
(0.0431)\end{array}$ & $\begin{array}{l}-0.0268 \\
(0.0517)\end{array}$ & $\begin{array}{l}0.1019 * \\
(0.0615)\end{array}$ & $\begin{array}{l}-0.1123 \\
(0.0754)\end{array}$ \\
\hline "not enough suitable employees" & $\begin{array}{c}-0.1300^{* *} \\
(0.0515)\end{array}$ & $\begin{array}{c}0.0572 \\
(0.0576)\end{array}$ & $\begin{array}{l}-0.1273 \\
(0.0833)\end{array}$ & $\begin{array}{c}0.0175 \\
(0.0947)\end{array}$ \\
\hline \multirow{2}{*}{$\begin{array}{l}\text { year-, region-, occup.-, ind.-FE } \\
\text { (year x region)-FE }\end{array}$} & yes & yes & yes & yes \\
\hline & yes & yes & yes & yes \\
\hline $\mathrm{R}^{2}$ & 0.1882 & 0.2868 & 0.2195 & 0.3326 \\
\hline $\mathrm{N}$ & 4,287 & 4,287 & 2,491 & 2,491 \\
\hline
\end{tabular}

Source: German Job Vacancy Survey 2005-2008.

Robust standard errors in brackets. ${ }^{* * *}$ indicates $p<0.01$; ** $p<0.05$; ${ }^{*} p<0.1$.

from the PEA but significant in explaining the number of applicants coming from the private market, suggest that the PEA distributes its applicants irrespective of these characteristics.

Differences in the variance of the number of applicants through the PEA and the private market

If it is true that the PEA coordinates applicants, we should also see that the number of applicants sent by the PEA to registered firms are more evenly distributed among vacancies than the number of applicants that the same firms receive through the private market. In other words, if the PEA reduces coordination frictions we should observe that the variance of the number of applicants sent by the PEA is smaller than the variance of the number of applicants that apply through the decentralized market. To calculate the respective variances, we use again the information on the number of applicants that a registered vacancy received through the PEA and compare it to the number of applicants that the same vacancy receives through other search channels.

The upper part of Table 3 shows the total and the residual variances of the $(\log )$ number of applicants for the full sample and the bottom part of Table 3 shows the respective results for the restricted 
sample. The residual variances of the (log) number of applicants are calculated based on the respective regressions in Table 2. Columns (1) and (2) show the respective variances of the (log) number of applicants. Column (3) presents the F-statistic of the variance-ratio-test, which equals the ratio of the variances in column (1) to column (2).

Table 3: Differences in the variances of the number of applicants between PEA and private market

\begin{tabular}{lccc}
\hline \hline & $\begin{array}{c}\text { Variance of the number of applicants }(\log ) \\
\text { private market }\end{array}$ & $\begin{array}{c}\text { PEA } \\
(1)\end{array}$ & $\begin{array}{c}\text { Variance-Ratio-Test } \\
\text { F-statistic }=\text { ratio }\end{array}$ \\
& & & $(3)$ \\
\hline \hline $\begin{array}{c}\text { full sample } \\
\text { total variance } \\
\text { residual variance }\end{array}$ & 1.8424 & 0.9487 & $\mathrm{~F}(5984,5984)=1.9421^{* * *}$ \\
$\begin{array}{c}\text { restricted sample } \\
\text { total variance } \\
\text { residual variance }\end{array}$ & 0.0127 & 0.0093 & $\mathrm{~F}(4270,4259)=1.3657^{* * *}$ \\
\hline \hline
\end{tabular}

Source: German Job Vacancy Survey 2005-2008.

Variance-Ratio-Text: $\mathrm{H}_{0}$ : Ratio $=1{ }^{* * *}$ indicates $p<0.01 ; * * p<0.05{ }^{*} p<0.1$.

Residual variances of the $(\log )$ number of applicants are based on the respective regressions in Table 2.

The total variance of the $(\log )$ number of applicants that registered vacancies receive from the private market is more than twice the total variance of the $(\log )$ number of applicants that the same vacancies receives from the PEA. The ratio of the variances of column (1) to column (2) (F-statistic) is statistically different from 1 with a confidence interval of $99 \%$. This holds for the full and the restricted sample. The result that the PEA distributes its unemployed more evenly than the private market is very robust. It holds for all subgroups irrespective of whether we take the full or the restricted sample as shown in Table 10 in the Appendix.

The respective ratio for the residual variances is between 1.2 and 1.4. The reason why the ratio of the residual variances is much smaller than the ratio of the total variances is due to the lower explanatory power of the variables in the regression for the number of applicants sent by the PEA compared to the explanatory power of the respective variables in the regression for the number of applicants from private market. The lower explanatory power in the regression for applicants sent by the PEA leads to a higher variance in the residuals. The ratio of the residual variances of column (1) to column (2) is still statistically different from one with a confidence interval of $99 \%$. This holds for the full and the restricted sample, but is no longer robust for all subgroups. In the full sample, the only exception is for vacancies requiring low qualification, in the restricted sample the exceptions are vacancies requiring low or high qualification and vacancies posted by firms with 20 to 49 employees or with more than 500 employees. Nevertheless, these results show that overall the PEA is successful in distributing job seekers more evenly than the private market. 


\section{Theoretical Analysis}

Motivated by the above empirical findings, we analyze in this section the implications of having a PEA in the labor market, which provides a market place with less (or no) coordination frictions. We do so by building a model, which allows firms to decide whether they want to register their vacancy with the PEA or search in the private market. Our theory also offers several important predictions about market outcomes that will be tested with our data in section 5 .

\subsection{Setup}

We consider an economy with a mass of unemployed workers and firms. We denote by $v \in(0, \infty)$ the population ratio of firms to unemployed workers. Each firm has one job vacancy that needs to be filled, and each worker wishes to find a job. There are two types of workers. A fraction $m$ of them have a normal character and can always produce an output normalized to 1 at any firm. The rest are workers with a difficult character. They are only productive, if they can get along with their potential boss. This happens with probability $\delta \in(0,1)$. So, with probability $1-\delta$, a match between a difficult worker and a firm produces 0. If a difficult worker fits (is suitable), he is as productive as a normal worker. While the information about whether or not a worker is suitable for a job is revealed at the stage of the job interview, the worker's type (normal or difficult) is private knowledge.

There are two channels through which matching between firms and unemployed workers can occur (see Figure 2). One is a Public Employment Agency (PEA), where all unemployed workers are registered in order to collect unemployment benefit (normalized to zero). We model the job-brokering service provided by the PEA as follows. All job applications by registered workers are coordinated so that workers and firms are brought together on a one by one basis. Denote by $a \in(0,1]$ the maximum number of matching pairs the PEA can propose. $a$ is a technological parameter. The other channel is a search market, which may be referred to as a decentralized or private market. Here, unlike in the PEA, search is costly for workers and job applications are not coordinated. Workers have to incur an individual specific search cost represented by $c$ drawn from a uniform distribution with support $[0,1]$. The parameter $c$ is uncorrelated with the worker's type. ${ }^{11}$ For now, we assume that $v$ is exogenously given and the firms' cost required to post a vacancy is normalized to zero for both markets. How workers search without coordination will be specified below.

The economy lasts only one period and has the following stages. In the first stage, firms decide whether to post their vacancy in the search market or the PEA. Once firms are registered, the PEA selects randomly $\min \{v \rho, a\}$ workers, where $\rho \in[0,1]$ is a fraction of firms registered with the PEA, and suggests each of them to match with one of the registered firms. In the second stage, all firms post simultaneously a wage at which they are willing to hire a worker. The wage posted in the search market is denoted by $w$, and the wage posted in the PEA by $w_{a}$. Having observed those wages, workers decide whether or not to enter the search market in the third stage. Once in the search market, workers

\footnotetext{
${ }^{11}$ See footnote 11 about how the correlation between $c$ and worker types can affect our result.
} 


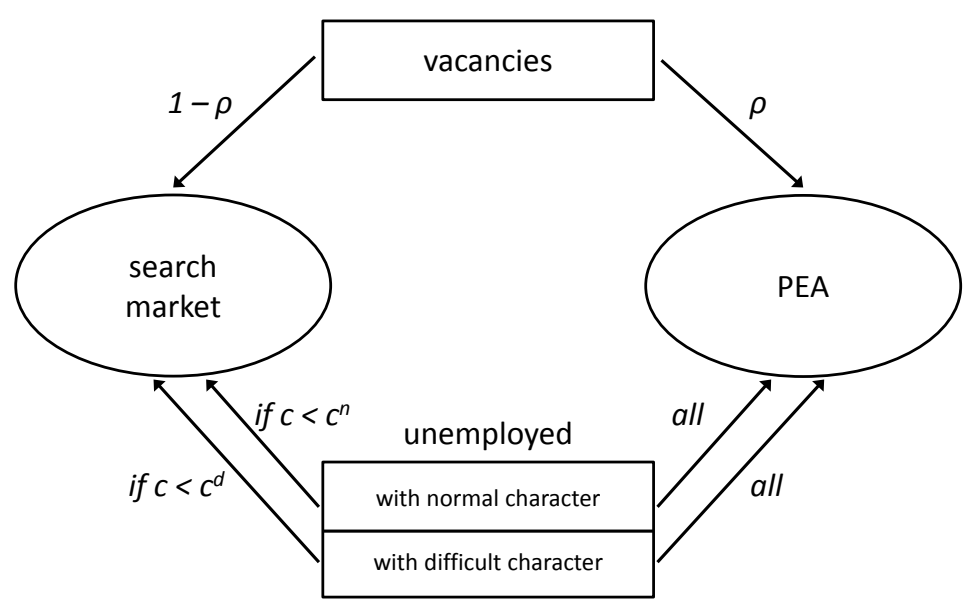

Figure 2: Search channels

must choose to which firm to send an application. Assuming that each worker can send only one application and that workers cannot coordinate their actions over which firm to apply, we investigate a symmetric equilibrium where all workers use the identical application strategy for any configuration of the announced wages. This is the standard notion of directed search equilibria, see e.g., Peters (1991, 2001), Moen (1997), Acemoglu and Shimer (1999), Shi (2001), Burdett, Shi and Wright (2001) and Guerrieri, Shimer and Wright (2010). Finally, given those applications in the search market or an assigned worker in the PEA, firms select a suitable applicant (if any) and make a job offer in the final stage. Those workers, who receive multiple offers, can select the highest wage. Once employed, production occurs and matched workers and firms receive their payoffs. Unmatched workers and firms get zero payoff.

In what follows, we construct a labor market equilibrium which has the following characteristics. A fraction $\rho \in[0,1)$ of firms registered with the PEA post a wage $w_{a}=0$ and a fraction $1-\rho$ of firms in the search market post a wage $w \in(0,1)$. All workers are registered in the PEA and accept the wage $w_{a}=0$ if it is the only offer they have received. A normal (difficult) worker enters a search market if and only if his search cost $c$ is no greater than a reservation value $c^{n}\left(c^{d}\right)$. Given the search behaviors of workers, each individual firm in the directed search market is characterized by a queue of applicants, denoted by $x$. The number of applicants $n=1,2,3, \ldots$ each individual firm receives is a random variable and follows from a Poisson distribution with density $\operatorname{Prob}[n=\tilde{n}]=\left(x^{\tilde{n}} e^{-x}\right) /(\tilde{n} !)$. The expected queue length $x$ satisfies,

$$
x=\frac{m c^{n}+(1-m) c^{d}}{v(1-\rho)},
$$

where the numerator equals the total number of workers in the search market $-m c^{n}$ normal and $(1-m) c^{d}$ difficult types -, while the denominator equals the total number of vacancies in the search market. Each worker with a normal character expects to be hired with probability $\eta(\tilde{x})$ in the search market (yet to be derived endogenously), whereas each worker with a difficult character expects to be 
hired with probability $\delta \eta(\tilde{x})$, where $\tilde{x}=\theta x$ and

$$
\theta \equiv \frac{m c^{m}+\delta(1-m) c^{u}}{m c^{m}+(1-m) c^{u}}
$$

is the share of suitable applicants in the search market. Hence,

$$
\tilde{x}=\frac{m c^{n}+\delta(1-m) c^{d}}{v(1-\rho)},
$$

defines the effective queue of applicants, measuring the expected queue of applicants suitable for the job. Each individual firm expects to employ a suitable worker (and can produce output 1) with probability $\tilde{x} \eta(\tilde{x})$ in the search market and with probability $\min \{1, a /(v \rho)\}\left(m\left(1-c^{n} \eta(\tilde{x})\right)+\delta(1-m)\left(1-c^{d} \delta \eta(\tilde{x})\right)\right)$ in the PEA, where $\min \{1, a /(v \rho)\}$ equals the probability of a registered firm to be assigned an unemployed worker by the PEA and $\left(m\left(1-c^{n} \eta(\tilde{x})\right)+\delta(1-m)\left(1-c^{d} \delta \eta(\tilde{x})\right)\right)$ the probability that the assigned worker is suitable and available, i.e., does not receive a better-paid offer in the private market. In the following we show that workers and firms have no incentive to deviate from the proposed search market equilibrium.

An equilibrium without active search market, i.e., $\rho=1$, will be characterized when we describe the first-stage entry decision.

\subsection{Labor market equilibrium with Public Employment Agency}

Workers' search decision Assuming for the moment the existence of an equilibrium, we first describe workers' search decision. In any equilibrium where $U^{n}\left(U^{d}\right)$ is the expected value of search for a worker with normal (difficult) character, the participation decision is described by a reservation value for the search cost, i.e.,

$$
\begin{aligned}
& c^{n}=U^{n}, \\
& c^{d}=U^{d},
\end{aligned}
$$

respectively. Since a worker with normal (difficult) character and search cost $c$ searches if and only if $c \leq c^{n}\left(c \leq c^{d}\right)$, the threshold values $c^{n}$ and $c^{d}$ determine the fraction of normal and difficult workers that choose to search in the private market. Figure 3 illustrates the search population of normal and difficult types of workers.

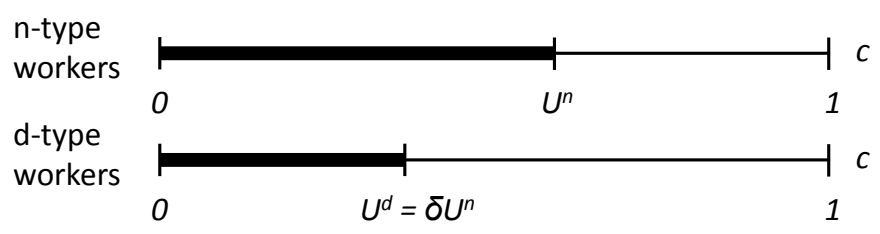

Figure 3: Participation in the search market

Given the participation decision, we now describe workers' application decision in the search market. We first need to compute the probability of a suitable applicant to get employed by a firm, $\eta(\tilde{x})$. This 
probability is derived as follows. Suppose a worker applies for a firm, where he turns out to be suitable, and $\tilde{n}$ other suitable workers also apply for it, which happens with probability $\left(\tilde{x}^{\tilde{n}} e^{-\tilde{x}}\right) /(\tilde{n} !)$. Then the worker is hired with probability $1 /(\tilde{n}+1) . \eta(\tilde{x})$ is the sum of this probability over all $\tilde{n}=0,1,2, \ldots$.

Lemma 1 The probability of a suitable applicant to get hired by a firm is given by

$$
\eta(\tilde{x})=\frac{1-e^{-\tilde{x}}}{\tilde{x}}
$$

where $\tilde{x} \in(0, \infty)$ is the effective queue of applicants given by (2).

Given $\eta(\tilde{x})$ derived above, consider a situation in which a firm in the search market deviates to a wage $w^{\prime}>0$, given that all other firms post $w$ with associated effective queue length $\tilde{x}$. Note that this deviation is a measure zero event for the entire market. Let $\tilde{x}^{\prime}$ be the effective queue of workers at this firm. Then, in any equilibrium where $U^{n}$ is the expected value of search for normal workers, the effective queue $\tilde{x}^{\prime}$ must satisfy,

$$
U^{n}=\eta\left(\tilde{x}^{\prime}\right) w^{\prime}
$$

because normal workers will be suitable to any firm. Similarly, for difficult workers it is,

$$
U^{d}=\delta \eta\left(x^{\prime}\right) w^{\prime}
$$

where the employment probability for a difficult worker is given by $\delta \eta\left(\tilde{x}^{\prime}\right)$. Observe that $\delta U^{n}=U^{d}$ and so $\delta c^{n}=c^{d}$. Equation (3) gives an implicit equation that determines $\tilde{x}^{\prime}=\tilde{x}\left(w^{\prime} \mid U^{n}\right)$ as a strictly increasing function of the wage $w^{\prime}$ given the market value $U^{n}$ (and $U^{d}$ ).

Firms' wage offers Given the search behaviors of workers described above, the next step is to characterize equilibrium wages. Given $w_{a}=0$ in the PEA (which will be verified shortly), we first derive an equilibrium wage in the search market. In any equilibrium where $U^{n}\left(U^{d}\right)$ is the market value of a normal (difficult) worker, the optimal wage of a firm, denoted by $w\left(U^{n}\right)$, satisfies,

$$
w\left(U^{n}\right)=\arg \max _{w^{\prime}} \tilde{x}\left(w^{\prime} \mid U^{n}\right) \eta\left(\tilde{x}\left(w^{\prime} \mid U^{n}\right)\right)\left(1-w^{\prime}\right) .
$$

Here, the firm with a wage $w^{\prime}$ and an effective queue $\tilde{x}^{\prime}$ expects to receive at least one suitable application with probability 1 - Prob. $(\tilde{n}=0)=1-e^{-\tilde{x}^{\prime}}=\tilde{x}\left(w^{\prime} \mid U^{n}\right) \eta\left(\tilde{x}\left(w^{\prime} \mid U^{n}\right)\right)$, in which case production occurs and the firm receives $1-w^{\prime}$. If there is no suitable applicant, then no production occurs.

Substituting out $w^{\prime}$ using equation (3), the objective function of a firm, denoted by $\Pi_{s}\left(\tilde{x}^{\prime}\right)$, can be written as,

$$
\Pi_{s}\left(\tilde{x}^{\prime}\right)=\tilde{x}^{\prime} \eta\left(\tilde{x}^{\prime}\right)-\tilde{x}^{\prime} U^{n}
$$

where $\tilde{x}^{\prime}=\tilde{x}\left(w^{\prime} \mid U^{n}\right)$ satisfies equation (3). The first-order condition is,

$$
\frac{\partial \Pi_{s}\left(\tilde{x}^{\prime}\right)}{\partial \tilde{x}^{\prime}}=e^{-\tilde{x}^{\prime}}-U^{n}=0 .
$$


The second order condition can be easily verified. By rearranging this condition using equation (3) one can obtain,

$$
w\left(U^{n}\right)=\frac{\tilde{x}^{\prime} e^{-\tilde{x}^{\prime}}}{1-e^{-\tilde{x}^{\prime}}} .
$$

In a directed search equilibrium, workers must be indifferent between any of the individual firms. This leads to,

$$
\begin{aligned}
w & =\frac{\tilde{x} e^{-\tilde{x}}}{1-e^{-\tilde{x}}}, \\
U^{n} & =e^{-\tilde{x}} .
\end{aligned}
$$

Hence, we have shown that given that $w_{a}=0$, the equilibrium wage in the search market $w>0$ is given by equation (4).

Given $w>0$ in the search market, we show next that the equilibrium wage in the PEA must satisfy $w_{a}=0$. Given that a proportion $\rho \in[0,1)$ of firms are in the PEA, the wage $w_{a}=0$ in the PEA yields an equilibrium profit,

$$
\Pi_{a}(\tilde{x})=\min \left\{\frac{a}{v \rho}, 1\right\}\left[m\left(1-c^{n} \eta(\tilde{x})\right)+\delta(1-m)\left(1-c^{d} \delta \eta(\tilde{x})\right)\right],
$$

where, given the probability of being allocated a worker, $\min \{a /(v \rho), 1\}$, the term $m\left(1-c^{n} \eta(\tilde{x})\right.$ ) (or $\left.(1-m)\left(1-c^{d} \delta \eta(\tilde{x})\right)\right)$ represents the number of normal (or difficult) workers, who do not receive a job offer in search markets and are willing to accept $w_{a}=0$.

The PEA matches registered workers and firms using its job-brokering mechanism. This allocation is independent of the wages offered by registered firms. The fact that registered firms cannot increase the PEA-internal matching probability $\min \{a /(v \rho), 1\}$ by offering a higher wage implies that registered firms will never compete among themselves. They will only compete with firms in the private market. This is the reason why a wage offer $w_{a}^{\prime} \in(0, w)$ cannot be profitable, since such a deviation implies a mere increase in the wage cost without improving the probability of hiring a suitable worker. If a deviating firm posts $w_{a}^{\prime} \geq w$, then it can hire an assigned suitable worker (if any), irrespective of whether the worker gets another offer in search markets. Hence, the best deviation $w_{a}^{\prime}=w$ yields the profit,

$$
\Pi_{a}^{\prime}=\min \left\{\frac{a}{v \rho}, 1\right\}[m+\delta(1-m)](1-w) .
$$

We show in the Appendix that deviating and paying the private market wage $w_{a}^{\prime}=w$ is not profitable, i.e., that $\Pi_{a}(\tilde{x})>\Pi_{a}^{\prime}$ for any $\tilde{x} \in(0, \infty)$. The reason, why the increase in the hiring probability associated with offering the private market wage $w_{a}^{\prime}=w$ is not able to compensate them for the higher wage cost, is that the expected suitability of applicants at the PEA is lower than the expected suitability of applicants in the decentralized market. It follows that registered firms offer only the reservation wage $w_{a}=0$, because the absence of PEA-internal wage competition due to the job-brokering mechanism does not force them to offer higher wages. Thus, $w_{a}=0$ is the unique equilibrium wage in the PEA. 
Lemma 2 Given any value of $\rho \in(0,1)$, the equilibrium wage is higher in the search market than in the PEA, $w>w_{a}$.

Firms' market choice In the first stage, firms decide whether to enter the PEA or the search market for hiring a worker. Firms will choose the market that offers the highest expected profit. Thereby, the equilibrium condition is given by,

$$
\rho=\left\{\begin{array}{cc}
0 & \text { if } \Pi_{a}(\tilde{x})<\Pi_{s}(\tilde{x}), \\
(0,1) & \text { if } \Pi_{a}(\tilde{x})=\Pi_{s}(\tilde{x}), \\
1 & \text { if } \quad \Pi_{a}>\Pi_{s},
\end{array}\right.
$$

where the equilibrium effective queue length in the search market $\tilde{x}=\tilde{x}(\rho)$ is given in equation (2) for $\rho \in[0,1)$. Given the expected queue length of suitable workers $\tilde{x}$, the equilibrium wages posted by firms in the private market, $w>0$ in equation (4), and the wage offered by registered firms, $w_{a}=0$, the equilibrium search values of type- $n$ workers $U^{n} \geq 0$ is given in equation (5), the equilibrium value of type- $d$ workers by $U^{d}=\delta U^{n}$, the equilibrium profit of firms searching in the PEA, $\Pi_{a}(\tilde{x})$ by equation (6), and the equilibrium profit of firms searching in the private market by,

$$
\Pi_{s}(\tilde{x})=1-e^{-\tilde{x}}-\tilde{x} e^{-\tilde{x}}
$$

If $\rho=1$, all firms are in the PEA. By offering the equilibrium wage $w_{a}=0$ they earn $\Pi_{a}=$ $\min \{a / v, 1\}[m+(1-m) \delta]$. Since no jobs are posted in the private market, only workers with zero search costs will participate in it. Hence, if a firm deviates and enters the search market with a wage $w^{\prime}=\varepsilon>0$, then the firm meets with a worker for sure, and makes profits, $\Pi_{s}=[m+(1-m) \delta](1-\varepsilon)$. This deviation is profitable if and only if $\Pi_{s}>\Pi_{a}$, or if and only if $a / v<1$ for an arbitrary small $\varepsilon$. Hence, an equilibrium without active search market, i.e., with $\rho=1$, can only exist if and only if $a / v \geq 1$, i.e., if the $\mathrm{PEA}$ is efficient enough.

Before we state our main result let us define,

$$
v^{*} \equiv\left(m+(1-m) \delta^{2}\right) \frac{e^{-\tilde{x}^{*}}}{\tilde{x}^{*}},
$$

where $\tilde{x}^{*}$ is a unique solution to $\Pi_{a}\left(\tilde{x}^{*}\right)=\Pi_{s}\left(\tilde{x}^{*}\right)$. We now summarize the main result of our analysis on labor market equilibria with the PEA.

Proposition 1 A search market equilibrium exists with an active PEA for $v>v^{*}$, and with an inactive PEA for $v \leq v^{*}$. This equilibrium is unique if and only if $v>a$. If $v \leq a$, then a pure PEA equilibrium also exists.

Remember that firms have to pay workers the higher wage $w>w_{a}=0$ to be able to induce costly search in the decentralized market (Lemma 2). The wage cost in the decentralized market is lower, 
when the number of firms $v$ is lower so that the search market is less tight and less competitive. Hence, Proposition 1 shows that the search market is used exclusively, $\rho=0$, when the number of vacancies $v$ and the PEA matching technology $a$ are not too high.

Our theory also establishes that some or all firms find it profitable to use the decentralized search market, instead of the PEA. This occurs for any values of the technological parameter, $a$, and the proportion of normal workers, $m .{ }^{12}$ The benefit of using the search market is to obtain a better selection of workers. This is represented by the following property (see Figure 4).

Corollary 1 Consider the search market equilibrium with an active PEA. The share of suitable workers among all the available applicants is higher in the search market than in the PEA, i.e.,

$$
\theta \equiv \frac{m+(1-m) \delta^{2}}{m+(1-m) \delta}>\frac{m\left(1-c^{n} \eta(\tilde{x})\right)+\delta(1-m)\left(1-c^{d} \delta \eta(\tilde{x})\right)}{m\left(1-c^{n} \eta(\tilde{x})\right)+(1-m)\left(1-c^{d} \delta \eta(\tilde{x})\right)},
$$

for any $m \in(0,1)$ and $\delta \in(0,1)$, where the R.H.S. is larger than the population share of suitable workers in the PEA, $m+(1-m) \delta$.

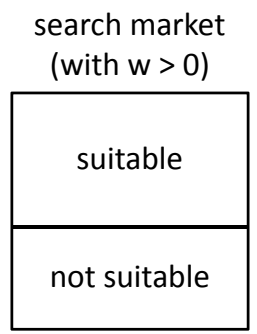

PEA

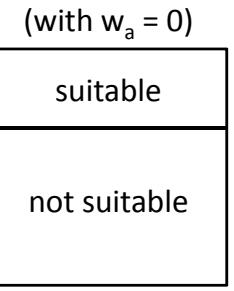

Figure 4: Selection of workers in search market and PEA

The following two corollaries are immediate consequences of Proposition 1, but derive further implications of the above equilibrium. First, comparing the above equilibrium with the one with no PEA (i.e. the search market is the only avenue of finding a worker/job), we can isolate the role of the PEA in our economy.

Corollary 2 The PEA in our economy creates a job opportunity to those who are discouraged from searching in the private market. This share of unemployed is larger for difficult types (the ones with a lower prospect of finding a job) than normal types.

The PEA gives an equal chance of having an interview to all unemployed workers. As stated above, this gives rise to the economic value of worker selection in the search market, which is essential to our theory.

\footnotetext{
${ }^{12}$ If the search costs distribution is relatively more skewed to the right for difficult types, then fewer difficult types would choose to participate in the search market, relative to the current setup of uncorrelated search costs with ex ante types. Hence, in this case, our result would be strengthened by taking into account the correlation. On the contrarily, if the search costs distribution is relatively more skewed to the left for difficult type, then more difficult types would participate in the search market, relative to the current setup, so the positive selection result may or may not hold.
} 
Corollary 3 For the values of technological parameter large enough to make the PEA match the short side, i.e., $a \geq \min \{v \rho, 1\}$, an equilibrium exists in which the search market is active.

This result contrasts with Pissarides (1979), who shows with homogeneous workers and exogenous wage that if search frictions are eliminated in the PEA, the private market collapses and all workers search via the PEA. In our framework with heterogeneous workers and endogenous wages, the better selection of workers in the search market ensures the existence of the decentralized search market even if the PEA manages to match the short side of the market.

Comparative statics We now examine the comparative statics of important parameters on the search decisions. For this purpose, we shall focus on the unique equilibrium with $v>\max \left\{a, v^{*}\right\}$, where both channels are active and examine the effect of parameter changes on the relative importance of each search channel.

Proposition 2 In a search market equilibrium with an active PEA, the fraction of vacancies registered in the PEA, $\rho$, and the queue length of suitable applicants in the private market, $\tilde{x}$, is increasing in the fraction of suitable workers (in $m$ and/or $\delta$ ) and in the matching technology of the PEA $a$, if $a<\rho v$.

With a higher $m$ and/or $\delta$ the fraction of suitable applicants among all unemployed increases. Consequently, the advantage of having a higher proportion of suitable workers in the search market compared to the PEA is reduced. This induces more firms to register their vacancy in the PEA and leads to a less tight search market for firms. Similarly, an improvement of the matching efficiency in the PEA, $a<\rho v$, will make the PEA more attractive, which leads to a less tight search market for firms. Clearly, such a policy will have no influence when the PEA is efficient enough already, $a \geq \rho v$.

\subsection{Extensions}

Search markets can offer firms a better selection of applicants than the PEA can do. This is exactly the mechanism that - we believe - makes search markets an attractive place to find a suitable worker. This is our answer to the question of why the costly and frictional search market is still used even when the costless and frictionless service of the PEA is available. We claim that this mechanism is robust and will go through under the following extensions.

Interviewing costs: So far we assumed that firms can elicit the suitability of a worker free of cost in an interview. Suppose now that a job interview requires a unit cost, denoted by $f \geq 0$, and that the total interviewing cost of a firm is proportional to the number of applicants it receives. ${ }^{13}$ The number

\footnotetext{
${ }^{13}$ The latter assumption implies that firms process all their applications. Alternatively, one can instead assume that interviews occur sequentially, and firms may not need to interview all their applicants. This can be incorporated into our setup as well. Note, however, that our aim here is to show that our main result survives despite costly interviews. We therefore adopt the most disadvantage technology to firms in the search market. Hence, the main result will be robust to a sequential interviewing technology.
} 
of applicants each firm receives (and interviews) is at most one in the PEA while it is random in the search market. Then, the expected costs of all interviews is $x f$ in the search market and so the expected profit of a firm is modified to

$$
\Pi_{s}=\tilde{x} \eta(\tilde{x})(1-w)-\frac{\tilde{x} f}{\theta},
$$

where $\tilde{x}=\theta x$ and $\theta \equiv \frac{m+(1-m) \delta^{2}}{m+(1-m) \delta}$ is the share of suitable applicants in the search market. As before, by considering a deviation $w^{\prime}$ and its associated queue $\tilde{x}^{\prime}=\tilde{x}\left(w^{\prime} \mid U^{n}\right)$ that satisfies equation (3), we obtain the first-order condition,

$$
\frac{\partial \Pi_{s}\left(\tilde{x}^{\prime}\right)}{\partial \tilde{x}^{\prime}}=e^{-\tilde{x}^{\prime}}-U^{n}-\frac{f}{\theta}=0,
$$

which leads to $w=\frac{\tilde{x}\left(e^{-\tilde{x}}-\frac{f}{\theta}\right)}{1-e^{-\tilde{x}}}$ and $U^{n}=e^{-\tilde{x}}-\frac{f}{\theta}$. The equilibrium profit in the search market is

$$
\Pi_{s}(\tilde{x})=1-e^{-\tilde{x}}-x e^{-\tilde{x}}
$$

where the effective queue is modified to

$$
\tilde{x}=\frac{m+(1-m) \delta^{2}}{v(1-\rho)}\left(e^{-\tilde{x}}-\frac{f}{\theta}\right) .
$$

This profit is now compared to the equilibrium profit in the PEA, $\Pi_{a}(\tilde{x})-f$. The equilibrium outcome is identical to the previous one when $f \rightarrow 0$. Hence, we have the following result.

Proposition 3 Suppose there is a cost of interviewing an applicant, $f>0$. Then, an active search market alongside an active PEA exists as long as $f$ is not too large.

Note, that the interview cost is passed on to unemployed workers. They have to pay for it via a lower wage in the search market. The interview cost can therefore be regarded as a fixed search cost component for workers. Thus, the search market will become inactive, if the cost is too high.

Free entry: The number of vacancies can be endogenized by free entry. Denote by $K \in(0,1)$ the cost of vacancy creation. Then, a free entry equilibrium has to satisfy

$$
\max \left\{\Pi_{a}, \Pi_{s}\right\}=K
$$

where $\Pi_{a}=\Pi_{a}(\tilde{x})$ is given by (6) and $\Pi_{s}=\Pi_{s}(\tilde{x})$ by (7). Whenever it exists, the search market effective queue $\tilde{x}$ is determined by this free entry condition. Hence, the conditions to determine the equilibrium given in Proposition 1 can now be stated in terms of the entry cost.

Proposition 4 With free entry of firms, a search market equilibrium with an active PEA exists for low values of $K$, and with an inactive PEA for high values of $K$. 
A search market exists for any $K \in(0,1)$, since free entry ensures that the queue length $\tilde{x}$ will adjust in such a way that profits in the search market are equal to entry costs. Higher entry cost will also reduce the number of firms registered at the PEA. However, profits in the PEA cannot adjust as flexibly as in the private market. The matching probability might be bounded by the technology of the PEA $a$. But even if the PEA is able to match all registered vacancies, the likelihood to be matched with an unsuitable worker could be so high that it is not worthwhile to enter the PEA.

Informational advantage in PEA: Our framework can be extended to analyze a situation in which the PEA is able to generate a higher suitability of applicants than in search markets. Suppose now that the PEA is able to observe the (ex ante) type of workers - normal or difficult -, and distributes normal workers prior to difficult workers. This may occur due to the frequent interactions between the registered unemployed and the case manager, backed by the accumulated knowledge from past experiences. Given such an ability of the PEA, if

$$
\min \{a, v \rho\} \leq m,
$$

then all applicants that the PEA distributes are suitable workers. This yields an equilibrium profit of a firm,

$$
\Pi_{a}(\tilde{x})=\min \left\{\frac{a}{v \rho}, 1\right\}\left(1-c^{n} \eta(\tilde{x})\right),
$$

where, since an applicant is suitable for sure, the term $1-c^{n} \eta(\tilde{x})$ represents the probability that an applicant assigned to the firm has not received a job offer in the search market and is willing to accept $w_{a}=0$. As before, any deviation from $w_{a}=0$ is not profitable.

The informational advantage of the PEA implies that an applicant sent by the PEA is suitable with probability 1 , which is strictly higher than the one in the active search market. However, such an informational advantage is not necessary if condition (9) does not hold true.

Proposition 5 Suppose that the PEA can observe the (ex ante) type of workers, and distribute normal workers prior to difficult workers. Then, search markets will become inactive if and only if $\min \{a, m\} \geq$ $v$.

The PEA can prevent workers and firms from using the private market if it is able to allocate a normal worker and therefore a suitable applicant to every registered vacancy. This is possible, if the PEA has the information advantage of knowing the type of a worker. Note, however, that even with such an ability, search markets become active when the population of normal type is scarce, i.e., $m$ is small. 


\section{Testing the theoretical implications}

\subsection{Differences among applicants and hired workers}

\section{Fraction of suitable applicants}

The main insight of our theory is the positive self-selection of workers into the private market (Corollary $1)$.

Implication 1: The fraction of suitable applicants is higher among applicants from the private market than among applicants sent by the PEA.

In Table 4 we investigate to which extent applicants sent by the PEA are less often regarded as suitable compared to those, who applied through the private market. To do so we can use the share of suitable applicants among the applicants sent by the PEA and among those, who applied through other channels, for each registered vacancy in the years 2005 to 2008 . Table 4 presents the respective difference results for the full and the restricted sample.

Table 4: Fraction of suitable applicants

\begin{tabular}{lcccc}
\hline \hline & \multicolumn{2}{c}{ Fraction of suitable applicants through } & & \\
& PEA & private market & difference & $\mathrm{N}$ \\
\hline \hline \multirow{3}{*}{ full sample } & & & \\
& 0.3384 & 0.3826 & $-0.0478^{* * *}$ & 3,270 \\
restricted sample & $(0.0060)$ & $(0.0058)$ & $(0.0082)$ & \\
& 0.3659 & 0.3919 & $-0.0223^{* *}$ & 1,867 \\
& $(0.0081)$ & $(0.0077)$ & $(0.0109)$ & \\
& & & \\
\hline \hline
\end{tabular}

Source: German Job Vacancy Survey 2005-2008.

Robust standard errors in brackets. *** indicates $p<0.01 ; * * p<0.05 ; * p<0.1$.

Table 4 shows that the fraction of suitable applicants sent by the PEA is significantly lower than the respective fraction of suitable workers, who applied through the private market. The difference is roughly $10 \%$. We also investigate the difference in the fraction of suitable applicants for different subgroups of vacancies in order to see whether the effect is driven by certain subgroups. Table 11 in the Appendix shows the respective difference estimates. The difference in the fraction of suitable applicants is statistically significant for most subgroups. The results are insignificant only for vacancies, which require a high qualification level and for vacancies posted by firms with more than 200 employees.

Given the observation that the fraction of suitable applicants sent by the PEA is lower than the respective fraction of suitable workers, who applied through the private market, and the evidence by the empirical literature using individual-level data, ${ }^{14}$ we believe that the pool of workers at the PEA

\footnotetext{
${ }^{14}$ Using a US household survey Blau and Robins (1990) show that unemployment insurance and welfare recipients are more likely to use the PEA. Using the Canadian Labor Force Survey Osberg (1993) emphasizes the importance to control
} 
is indeed a negative selection of the average worker. Our analysis is the first to provide evidence for this negative self-selection from the firms' perspective. This is important, because the worker-based evidence in the literature mentioned above does not necessarily imply our result. To see this note that it could be that the PEA has an information advantage as discussed in Proposition 5. If the PEA has such an information advantage, registered firms could receive more applications from suitable workers. The fact that our results show the opposite suggests that the PEA has no informational advantage over the private market.

\section{Differences in the characteristics of hired workers}

In our theory we assumed that all suitable applicants are equally productive. In reality, suitable applicants might still differ to some degree in productivity. Given the adverse selection of applicants predicted by our theory, one could expect that workers hired through the PEA are on average less productive. We nevertheless stick with our assumption and formulate the following hypothesis:

Implication 2: Workers hired through the PEA are as productive as workers hired through the private market.

We do not have a direct measure of productivity. The survey only asks whether the newly hired worker's qualification or experience level is above or below the firm's expectation. We see that $8.3 \%$ $(10.9 \%)$ of all firms report that the newly hired worker has a qualification (experience) level below expectations and $5.3 \%(4.2 \%)$ of all firms report that the newly hired worker has a qualification (experience) level above expectations. This suggests that firms interpret this question such that they are asked to compare the newly hired worker with some reference point. In this sense the survey question contains some information about the relative productivity of newly hired workers.

Table 5 presents OLS-regression results for the indicator variables "qualification above/below expectation" and "experience above/below expectation" for the full and restricted sample, respectively. The German Job Vacancy Survey provides information on the age, the gender and the previous employment status of the hired worker. The information on age and the job's qualification requirement allows us to calculate the potential labor market experience of the hired worker. To do so we use job qualification requirements to approximate the years of schooling. Variables that control for vacancy characteristics include the required qualification and experience level, whether it is a permanent or temporary and full-time or part-time job. We also include an indicator variable, which captures whether the vacancy was registered with the PEA or not (PEA search channel). On the firm level we control for the number of employees ( $\log$ ) as well as the economic condition of a firm as captured by the binary indicator variables "low sales", "financial constraints", and "not enough suitable employees". We also control for 
Table 5: Characteristics of hired workers

\begin{tabular}{|c|c|c|c|c|}
\hline & \multicolumn{4}{|c|}{ OLS-Regressions } \\
\hline & \multirow{2}{*}{\multicolumn{2}{|c|}{$\begin{array}{c}\text { Qualification } \\
\text { above/below expectation }\end{array}$}} & \multirow{2}{*}{\multicolumn{2}{|c|}{$\begin{array}{c}\text { Experience } \\
\text { above/below expectation }\end{array}$}} \\
\hline & & & & \\
\hline & full-sample & restr. sample & full-sample & restr. sample \\
\hline & (1) & $(2)$ & (3) & $(4)$ \\
\hline PEA hiring channel & $\begin{array}{c}0.0066 \\
(0.0081)\end{array}$ & $\begin{array}{c}0.0060 \\
(0.0099)\end{array}$ & $\begin{array}{c}0.0029 \\
(0.0083)\end{array}$ & $\begin{array}{c}-0.0018 \\
(0.0102)\end{array}$ \\
\hline PEA search channel & $\begin{array}{c}-0.0234^{* * *} \\
(0.0059)\end{array}$ & $\begin{array}{c}-0.0219^{* * *} \\
(0.0071)\end{array}$ & $\begin{array}{c}-0.0323^{* * *} \\
(0.0061)\end{array}$ & $\begin{array}{c}-0.0245^{* * *} \\
(0.0074)\end{array}$ \\
\hline worker's experience & $\begin{array}{c}0.0025^{* * *} \\
(0.0009)\end{array}$ & $\begin{array}{c}0.0023^{* * *} \\
(0.0011)\end{array}$ & $\begin{array}{c}0.0066^{* * *} \\
(0.0010)\end{array}$ & $\begin{array}{c}0.0059 * * * \\
(0.0012)\end{array}$ \\
\hline worker's experience 2 & $\begin{array}{l}-0.0000 \\
(0.0000)\end{array}$ & $\begin{array}{l}-0.0000 \\
(0.0000)\end{array}$ & $\begin{array}{c}-0.0000^{*} \\
(0.0000)\end{array}$ & $\begin{array}{l}-0.0000 \\
(0.0000)\end{array}$ \\
\hline female & $\begin{array}{c}0.0087 \\
(0.0065)\end{array}$ & $\begin{array}{c}0.0053 \\
(0.0077)\end{array}$ & $\begin{array}{c}0.0123 * * * \\
(0.0068)\end{array}$ & $\begin{array}{c}0.0075 \\
(0.0081)\end{array}$ \\
\hline previously unemployed & $\begin{array}{c}-0.0461^{* * * *} \\
(0.0060)\end{array}$ & $\begin{array}{c}-0.0344^{* * *} \\
(0.0073)\end{array}$ & $\begin{array}{c}-0.0542^{* * *} \\
(0.0062)\end{array}$ & $\begin{array}{c}-0.0385^{* * * *} \\
(0.0075)\end{array}$ \\
\hline low qualification & $\begin{array}{c}0.0132 \\
(0.0103)\end{array}$ & $\begin{array}{c}0.0186 \\
(0.0129)\end{array}$ & $\begin{array}{c}-0.0004 \\
(0.0104)\end{array}$ & $\begin{array}{c}0.0119 \\
(0.0126)\end{array}$ \\
\hline high qualification & $\begin{array}{c}0.0336 * * * \\
(0.0090)\end{array}$ & $\begin{array}{c}0.0264^{* *} \\
(0.0105)\end{array}$ & $\begin{array}{c}0.0240 * * \\
(0.0095)\end{array}$ & $\begin{array}{c}0.0340 * * * \\
(0.0110)\end{array}$ \\
\hline occupation specific experience & $\begin{array}{c}0.0011 \\
(0.0055)\end{array}$ & $\begin{array}{c}-0.0022 \\
(0.0066)\end{array}$ & $\begin{array}{c}0.0190 * * * \\
(0.0058)\end{array}$ & $\begin{array}{c}0.0151^{* *} \\
(0.0069)\end{array}$ \\
\hline permanent & $\begin{array}{c}0.0142^{* * *} \\
(0.0053)\end{array}$ & $\begin{array}{c}0.0201^{* * *} \\
(0.0063)\end{array}$ & $\begin{array}{c}0.0059 \\
(0.0055)\end{array}$ & $\begin{array}{c}0.0145^{* *} \\
(0.0065)\end{array}$ \\
\hline full-time & $\begin{array}{c}-0.0174^{* *} \\
(0.0069)\end{array}$ & $\begin{array}{c}-0.0031 \\
(0.0082)\end{array}$ & $\begin{array}{l}-0.0077 \\
(0.0071)\end{array}$ & $\begin{array}{c}0.0001 \\
(0.0085)\end{array}$ \\
\hline weekend-work & $\begin{array}{c}-0.0028 \\
(0.0084)\end{array}$ & $\begin{array}{c}-0.0042 \\
(0.0099)\end{array}$ & $\begin{array}{l}-0.0020 \\
(0.0088)\end{array}$ & $\begin{array}{l}-0.0065 \\
(0.0105)\end{array}$ \\
\hline firm size (log) & $\begin{array}{c}0.0095^{* * *} \\
(0.0017)\end{array}$ & $\begin{array}{c}0.0070 * * * \\
(0.0020)\end{array}$ & $\begin{array}{c}0.0109 * * * \\
(0.0018)\end{array}$ & $\begin{array}{c}0.0088^{* * *} * \\
(0.0021)\end{array}$ \\
\hline "financial constraints" & $\begin{array}{c}-0.0085 \\
(0.0104)\end{array}$ & $\begin{array}{c}-0.0148 \\
(0.0124)\end{array}$ & $\begin{array}{c}-0.0051 \\
(0.0108)\end{array}$ & $\begin{array}{c}-0.0188 \\
(0.0130)\end{array}$ \\
\hline "low sales" & $\begin{array}{c}0.0020 \\
(0.0078)\end{array}$ & $\begin{array}{c}0.0055 \\
(0.0096)\end{array}$ & $\begin{array}{l}-0.0068 \\
(0.0081)\end{array}$ & $\begin{array}{c}-0.0107 \\
(0.0100)\end{array}$ \\
\hline "not enough suitable employees" & $\begin{array}{c}-0.1090 * * * \\
(0.0116)\end{array}$ & $\begin{array}{c}-0.0985 * * * \\
(0.0173)\end{array}$ & $\begin{array}{c}-0.1198 * * * \\
(0.0118)\end{array}$ & $\begin{array}{c}-0.1052^{* * *} \\
(0.0173)\end{array}$ \\
\hline \multirow{2}{*}{$\begin{array}{l}\text { year-, region-, occup.-, ind.-FE } \\
\text { (year x region)-FE }\end{array}$} & yes & yes & yes & yes \\
\hline & yes & yes & yes & yes \\
\hline $\mathrm{R}^{2}$ & 0.0469 & 0.0492 & 0.0587 & 0.0553 \\
\hline $\mathrm{N}$ & 22,501 & 14,041 & 22,501 & 14,041 \\
\hline
\end{tabular}

Source: German Job Vacancy Survey 2005-2010.

Robust standard errors in brackets. *** indicates $p<0.01 ; * * p<0.05 ;{ }^{*} p<0.1$.

year-, region-, occupation-, and industry-fixed effects as well as for year and region interaction terms, which capture all trends on the regional level.

In the first line we present the coefficients for the indicator variable, which equals one if the worker was hired through the PEA. This coefficient has to be interpreted conditional on having registered the vacancy with the PEA (second line: PEA search channel). The coefficients for the "PEA hiring channel" indicator variable are insignificant for both the qualification and the experience level as shown in columns (1) and (2) and columns (3) and (4), respectively. This suggests that workers hired through 
the PEA are regarded as qualified and experienced as workers hired through the private market. ${ }^{15}$ In Table 12 in the Appendix we show that this result holds for all subgroups.

Although registered firms regard the pool of applicants coming from the PEA as less suitable, our results regarding the characteristics of the hired workers suggest that they only hire workers, who are equally qualified and experienced, i.e., suitable, as those workers hired through the private market. This is perfectly in line with our theory.

\subsection{Wage differences between registered and unregistered vacancies}

Wages paid by registered compared to unregistered vacancies

The evidence that the PEA reduces coordination frictions, suggests that the probability to receive an applicant from the PEA should be less dependent on the offered wage than the respective probability in the private market. Registered firms therefore do not need to compete in wages in order to attract workers. This suggests that wages offered and paid by registered vacancies should be lower than wages offered and paid by firms in the private market.

Implication 3: Wages posted and paid by firms registered with the PEA are lower than wages posted and paid by firms only active in the private market.

To investigate this hypothesis we use the German Job Vacancy Survey in 2014, which - for the first time - collected the information on the wages paid to workers hired for the vacancy. A first look at the descriptive statistics is affirmative. A worker hired for a job, which was registered with the PEA, is on average paid 12.48 Euros per hour. This is 1.36 Euro less than the 13.84 Euros per hour, which workers are paid by at jobs offered purely in the private market.

The descriptive difference could be driven by the heterogeneity between registered and unregistered vacancies. In the OLS-regressions in Table 6 we control for the same worker-, firm-, and vacancy characteristics as in Table 5. For the year 2014 we also know, whether the firm was unionized or not. The results show that wages paid by firms that registered their vacancy at the PEA are $3 \%$ to $5 \%$ lower than wages paid by unregistered vacancies. Note, that we controlled for the previous labor market status of the hired worker. Thus, the result cannot be driven by the effect that registered vacancies are more likely to hire unemployed workers, who have a lower outside option, compared to unregistered vacancies.

Table 6 presents in columns (1) and (2) the OLS-regression results on (log) wages for the full sample and in columns (3) and (4) for the restricted sample, where we exclude all those observations where firms agreed on an applicant after the intended starting date of the employment contract. The restricted sample should therefore rule out reverse causality, i.e., that firms, which were not successful in filling the vacancy before the intended starting date of the employment contract, adjusted their wage offer and

\footnotetext{
${ }^{15}$ The fact that registered firms are more likely to report that their hired workers have less qualification and less experience (PEA search channel) suggests that registered firms hire less experienced workers from both channels, private market and PEA.
} 
Table 6: Wage difference between registered and unregistered vacancies

\begin{tabular}{|c|c|c|c|c|}
\hline & \multirow{2}{*}{\multicolumn{2}{|c|}{$\begin{array}{l}\text { OLS-Regressions: Wages }(\log ) \\
\text { full sample }\end{array}$}} & \multirow{2}{*}{\multicolumn{2}{|c|}{$\begin{array}{c}\text { OLS-Regressions: Wages }(\log ) \\
\text { restricted sample }\end{array}$}} \\
\hline & & & & \\
\hline & (1) & $(2)$ & (3) & (4) \\
\hline PEA search channel & $\begin{array}{c}-0.0346^{* * *} \\
(0.0068)\end{array}$ & $\begin{array}{c}-0.0286^{* * *} \\
(0.0074)\end{array}$ & $\begin{array}{c}-0.0537^{* * *} \\
(0.0114)\end{array}$ & $\begin{array}{c}-0.0471^{* * * *} \\
(0.0125)\end{array}$ \\
\hline PEA hiring channel & & $\begin{array}{c}-0.0216^{* *} \\
(0.0107)\end{array}$ & & $\begin{array}{l}-0.0236 \\
(0.0186)\end{array}$ \\
\hline previously unemployed & $\begin{array}{c}-0.0638^{* * *} \\
(0.0077)\end{array}$ & $\begin{array}{c}0.0613^{* * *} \\
(0.0078)\end{array}$ & $\begin{array}{c}-0.0692^{* * *} \\
(0.0131)\end{array}$ & $\begin{array}{c}-0.0667^{* * *} \\
(0.0133)\end{array}$ \\
\hline worker's experience & $\begin{array}{c}0.0115^{* * *} \\
(0.0012)\end{array}$ & $\begin{array}{c}0.0115^{* * * *} \\
(0.0012)\end{array}$ & $\begin{array}{c}0.0122^{* * *} \\
(0.0019)\end{array}$ & $\begin{array}{c}0.0121 * * * \\
(0.0019)\end{array}$ \\
\hline worker's experience ${ }^{2}$ & $\begin{array}{c}-0.0218^{* * *} \\
(0.0028)\end{array}$ & $\begin{array}{c}-0.0217^{* * *} \\
(0.0028)\end{array}$ & $\begin{array}{c}-0.0228^{* * *} \\
(0.0047)\end{array}$ & $\begin{array}{c}-0.0227^{* * *} \\
(0.0047)\end{array}$ \\
\hline female & $\begin{array}{c}-0.0728^{* * *} \\
(0.0095)\end{array}$ & $\begin{array}{c}-0.0729 * * * \\
(0.0095)\end{array}$ & $\begin{array}{c}-0.0883^{* * *} \\
(0.0148)\end{array}$ & $\begin{array}{c}-0.0887^{* * *} \\
(0.0148)\end{array}$ \\
\hline low qualification & $\begin{array}{c}-0.0818^{* * * *} \\
(0.0140)\end{array}$ & $\begin{array}{c}-0.0818^{* * *} \\
(0.0140)\end{array}$ & $\begin{array}{c}-0.0626^{* * * *} \\
(0.0227)\end{array}$ & $\begin{array}{c}-0.0625^{* * *} \\
(0.0228)\end{array}$ \\
\hline high qualification & $\begin{array}{c}0.2172^{* * * *} \\
(0.0164)\end{array}$ & $\begin{array}{c}0.2168^{* * *} \\
(0.0164)\end{array}$ & $\begin{array}{c}0.2007^{* * * *} \\
(0.0258)\end{array}$ & $\begin{array}{c}0.2003^{* * *} * \\
(0.0258)\end{array}$ \\
\hline occupation specific experience & $\begin{array}{c}0.0822^{* * *} \\
(0.0077)\end{array}$ & $\begin{array}{c}0.0818^{* * *} \\
(0.0077)\end{array}$ & $\begin{array}{c}0.0880 * * * \\
(0.0119)\end{array}$ & $\begin{array}{c}0.0877^{* * *} \\
(0.0118)\end{array}$ \\
\hline permanent & $\begin{array}{c}0.0540 * * * \\
(0.0070)\end{array}$ & $\begin{array}{c}0.0537 * * * \\
(0.0070)\end{array}$ & $\begin{array}{c}0.0656 * * * \\
(0.0112)\end{array}$ & $\begin{array}{c}0.0654^{* * * *} \\
(0.0112)\end{array}$ \\
\hline full-time & $\begin{array}{c}0.2669 * * * \\
(0.0174)\end{array}$ & $\begin{array}{c}0.2666^{* * *} \\
(0.0174)\end{array}$ & $\begin{array}{c}0.2905 * * * \\
(0.0265)\end{array}$ & $\begin{array}{c}0.2906^{* * * *} \\
(0.0265)\end{array}$ \\
\hline weekend-work & $\begin{array}{c}-0.0221^{*} \\
(0.0115)\end{array}$ & $\begin{array}{c}-0.0225^{*} \\
(0.0115)\end{array}$ & $\begin{array}{c}0.0018 \\
(0.0184)\end{array}$ & $\begin{array}{l}0.0011 \\
(0.0184)\end{array}$ \\
\hline unionized firm & $\begin{array}{c}0.0699 * * * \\
(0.0077)\end{array}$ & $\begin{array}{c}0.0694^{* * * *} \\
(0.0077)\end{array}$ & $\begin{array}{c}0.0716 * * * \\
(0.0123)\end{array}$ & $\begin{array}{c}0.0712^{* * * *} \\
(0.0123)\end{array}$ \\
\hline firm size (log) & $\begin{array}{c}0.0312^{* * *} \\
(0.0032)\end{array}$ & $\begin{array}{c}0.0309 * * * \\
(0.0032)\end{array}$ & $\begin{array}{c}0.0390 * * * \\
(0.0050)\end{array}$ & $\begin{array}{c}0.0384^{* * * *} \\
(0.0051)\end{array}$ \\
\hline "financial constraints" & $\begin{array}{l}-0.0260 \\
(0.0176)\end{array}$ & $\begin{array}{l}-0.0256 \\
(0.0176)\end{array}$ & $\begin{array}{c}-0.0163 \\
(0.0311)\end{array}$ & $\begin{array}{c}-0.0154 \\
(0.0311)\end{array}$ \\
\hline "low sales" & $\begin{array}{c}0.0044 \\
(0.0118)\end{array}$ & $\begin{array}{c}0.0045 \\
(0.0118)\end{array}$ & $\begin{array}{l}-0.0028 \\
(0.0192)\end{array}$ & $\begin{array}{c}-0.0031 \\
(0.0192)\end{array}$ \\
\hline "not enough suitable employees" & $\begin{array}{c}0.0039 \\
(0.0092)\end{array}$ & $\begin{array}{c}0.0034 \\
(0.0093)\end{array}$ & $\begin{array}{c}0.0240 \\
(0.0174)\end{array}$ & $\begin{array}{c}0.0236 \\
(0.0174)\end{array}$ \\
\hline region-, occup.-, ind.-FE & yes & yes & yes & yes \\
\hline $\mathrm{R}^{2}$ & 0.6666 & 0.6668 & 0.6992 & 0.6994 \\
\hline $\mathrm{N}$ & 6,359 & 6,359 & 3,141 & 3,141 \\
\hline
\end{tabular}

Source: German Job Vacancy Survey 2014.

Robust standard errors in brackets. ${ }^{* * *}$ indicates $p<0.01$; ${ }^{* *} p<0.05 ;{ }^{*} p<0.1$.

search strategy by registering the vacancy with the PEA. We therefore regard the results in columns (3) and (4) as being more reliable.

If we focus on our preferred specification in columns (3) and (4). Comparing columns (3) with column (4) shows that the effect is robust to including an indicator variable for cases where the worker is hired through the PEA. The fact that the coefficient on the "PEA hiring channel" indicator variable is statistically insignificant suggests that wages do not depend on whether the worker was hired through the PEA or not. What matters is whether the firm registered its vacancy with the PEA, i.e., used the PEA as a search channels. Put differently, the insignificance of the "PEA hiring channel" suggest that 
firms do not adjust their wage depending on the channel through which the preferred worker contacted them, but commit to a wage when deciding whether or not to register the vacancy with the PEA. This is well in line with our directed search framework in the theory part.

The PEA search channel wage gap can also be found for most subgroups as shown in Table 13 in the Appendix. The wage gap only vanishes for jobs requiring low and high qualifications, and for jobs offered by firms with less than 20 and more than 200 employees.

Differences in experiencing difficulties due to "high wage demands"

Table 7: Recruiting difficulties due to "high wage demands"

\begin{tabular}{|c|c|c|c|c|}
\hline & \multicolumn{4}{|c|}{$\begin{array}{l}\text { Recruiting difficulties due to "high wage demands" } \\
\text { Probit Regressions: Marginal Effects }\end{array}$} \\
\hline & \multicolumn{2}{|c|}{ full sample } & \multicolumn{2}{|c|}{ restricted sample } \\
\hline & $(1)$ & $(2)$ & $(3)$ & $(4)$ \\
\hline PEA search channel & $\begin{array}{c}0.0338^{* * *} \\
(0.0034)\end{array}$ & $\begin{array}{c}0.0377^{* * *} \\
(0.0038)\end{array}$ & $\begin{array}{c}0.0290^{* * *} \\
(0.0039)\end{array}$ & $\begin{array}{c}0.0335 * * * \\
(0.0043)\end{array}$ \\
\hline PEA hiring channel & & $\begin{array}{c}-0.0111^{* *} \\
(0.0045)\end{array}$ & & $\begin{array}{c}-0.0133^{* *} \\
(0.0052)\end{array}$ \\
\hline low qualification & $\begin{array}{c}0.0257^{* * *} \\
(0.0061)\end{array}$ & $\begin{array}{c}0.0259 * * * \\
(0.0061)\end{array}$ & $\begin{array}{l}0.0138^{*} \\
(0.0072)\end{array}$ & $\begin{array}{c}0.0140^{*} \\
(0.0073)\end{array}$ \\
\hline high qualification & $\begin{array}{c}-0.0149^{* *} \\
(0.0061)\end{array}$ & $\begin{array}{c}-0.0152^{* *} \\
(0.0061)\end{array}$ & $\begin{array}{c}-0.0124^{*} \\
(0.0070)\end{array}$ & $\begin{array}{c}-0.0128^{*} \\
(0.0070)\end{array}$ \\
\hline occupation specific experience & $\begin{array}{c}0.0057^{*} \\
(0.0034)\end{array}$ & $\begin{array}{l}0.0056^{*} \\
(0.0034)\end{array}$ & $\begin{array}{c}0.0034 \\
(0.0038)\end{array}$ & $\begin{array}{c}0.0032 \\
(0.0038)\end{array}$ \\
\hline permanent & $\begin{array}{c}0.0037 \\
(0.0035)\end{array}$ & $\begin{array}{c}0.0032 \\
(0.0035)\end{array}$ & $\begin{array}{c}0.0009 \\
(0.0039)\end{array}$ & $\begin{array}{c}0.0002 \\
(0.0039)\end{array}$ \\
\hline full-time & $\begin{array}{c}0.0099 * * \\
(0.0047)\end{array}$ & $\begin{array}{c}0.0099 * * \\
(0.0047)\end{array}$ & $\begin{array}{c}0.0028 \\
(0.0051)\end{array}$ & $\begin{array}{c}0.0026 \\
(0.0051)\end{array}$ \\
\hline weekend-work & $\begin{array}{c}0.0080 \\
(0.0052)\end{array}$ & $\begin{array}{c}0.0074 \\
(0.0052)\end{array}$ & $\begin{array}{c}0.0083 \\
(0.0060)\end{array}$ & $\begin{array}{c}0.0073 \\
(0.0060)\end{array}$ \\
\hline firm size $(\log )$ & $\begin{array}{c}-0.0034^{* * *} \\
(0.0013)\end{array}$ & $\begin{array}{c}-0.0037^{* * *} \\
(0.0013)\end{array}$ & $\begin{array}{c}-0.0050 * * * \\
(0.0014)\end{array}$ & $\begin{array}{c}-0.0053^{* * * *} \\
(0.0014)\end{array}$ \\
\hline "financial constraints" & $\begin{array}{c}0.0281^{* * *} \\
(0.0056)\end{array}$ & $\begin{array}{c}0.0284^{* * * *} \\
(0.0056)\end{array}$ & $\begin{array}{c}0.0206 * * * \\
(0.0064)\end{array}$ & $\begin{array}{c}0.0211^{* * *} * \\
(0.0064)\end{array}$ \\
\hline "low sales" & $\begin{array}{c}0.0233^{* * *} \\
(0.0042)\end{array}$ & $\begin{array}{c}0.0232 * * * \\
(0.0042)\end{array}$ & $\begin{array}{c}0.0142 * * * \\
(0.0049)\end{array}$ & $\begin{array}{c}0.0142^{* * *} * \\
(0.0049)\end{array}$ \\
\hline "not enough suitable employees" & $\begin{array}{c}0.0595^{* * *} \\
(0.0045)\end{array}$ & $\begin{array}{c}0.0586^{* * *} \\
(0.0045)\end{array}$ & $\begin{array}{c}0.0505^{* * *} * \\
(0.0056)\end{array}$ & $\begin{array}{c}0.0496^{* * *} \\
(0.0056)\end{array}$ \\
\hline year-, region-, occup.-, ind.-FE & yes & yes & yes & yes \\
\hline (year $\mathrm{x}$ region)-FE & yes & yes & yes & yes \\
\hline Pseudo- $R^{2}$ & 0.1248 & 0.1254 & 0.1631 & 0.1646 \\
\hline $\mathrm{N}$ & 19,263 & 19,263 & 10,281 & 10,281 \\
\hline
\end{tabular}

Source: German Job Vacancy Survey 2005-2010.

Robust standard errors in brackets. ${ }^{* * *}$ indicates $p<0.01$; ${ }^{* *} p<0.05 ;{ }^{*} p<0.1$.

The German Job Vacancy Survey also contains information on whether a firm had difficulties in filling the vacancy because its applicants demanded higher wages. This information can shed light not only into the question on whether registered vacancies offer lower wages than unregistered vacancies, it also provides information on whether a worker receives different wage offers from registered compared to 
unregistered vacancies.

Given the evidence presented above that registered vacancies pay lower wages, we expect that they are also more likely to experience difficulties in the hiring process due to higher wage demands by applicants. Registered vacancies experience such difficulties in $7.7 \%$ of all cases, while unregistered vacancies experience such difficulties only in $3.9 \%$ of all cases.

We use the same job and firm characteristics as control variables as in Table 6. We do not include individual characteristics of the hired worker, since the question underlying the indicator variable "difficulties due to high wage demands" explicitly addresses the experience with all applicants.

The results in Table 7 indicate a strong positive correlation between registering a vacancy with the PEA and experiencing difficulties in the recruitment process due to high wage demands by applicants. Thus, having registered the vacancy with the PEA (and posted a respective wage) is associated with an increase in the probability to experience difficulties due to higher wage demands by around 3 percentage points. The effect is reduced slightly if we exclude all observations where firms agreed on an applicant after the intended starting date of the employment contract (restricted sample in columns (3) and (4)). Firms which hire a worker, who was first contacted through the PEA (PEA hiring channel), report that they were less likely to experience difficulties due to higher wage demands. The same pattern holds if we divide the sample into different subgroups as shown in Tables 14 in the Appendix.

\subsection{Testing factors influencing the choice of registering a vacancy}

Proposition 2 states that a higher meeting probability in the PEA, $a$, as well as a higher fraction of suitable applicants, $m$ and/or $\delta$, increases the probability that a firm registers with the PEA, $\rho$. A higher meeting probability in the PEA, $a$ can empirically be measured by a higher number of applicants send by the PEA to each vacancy. A higher fraction of suitable workers in the pool of unemployed can be measured by the fraction of suitable applicants coming from the PEA.

Another comparative static result is contained in Proposition 1 (existence), which states that the PEA is active if the number of vacancies (relative to the number of unemployed workers, which we normalized to one in our theory) is high, and that all firms will chose to post their vacancy in the private market if the number of vacancies (relative to the number of unemployed workers) is low. In other words, the probability to register a vacancy with the PEA decreases with the expected number of applicants per vacancy in the private market. Our theory also suggests the following ceteris paribus result for the expected fraction of suitable applicants: A higher expected fraction of suitable applicants in the private market increases the profits of posting a vacancy in the private market and therefore decreases the probability to register the vacancy with the PEA.

Implication 4: Firms are more likely to register with the PEA, when the expected number of applicants and the expected fraction of suitable applicants coming from the private market is low (coming from the PEA is high). 
Table 8: Comparative statics: PEA used as search channel

\begin{tabular}{|c|c|c|}
\hline & $\begin{array}{l}\text { Ordered-Pro } \\
\text { full sample } \\
\text { (1) }\end{array}$ & $\begin{array}{l}\text { Marginal Effects } \\
\text { restricted sample } \\
(2)\end{array}$ \\
\hline \multicolumn{3}{|l|}{ private market } \\
\hline Exp. number of appl. (log) & $\begin{array}{c}-0.1372^{* * * *} \\
(0.0176)\end{array}$ & $\begin{array}{c}-0.1889^{* * *} \\
(0.0205)\end{array}$ \\
\hline Exp. fraction of suitable appl. & $\begin{array}{c}-0.4575^{* * *} \\
(0.0174)\end{array}$ & $\begin{array}{c}-0.4166^{* * *} \\
(0.0208)\end{array}$ \\
\hline \multicolumn{3}{|l|}{ PEA } \\
\hline Exp. number of appl. (log) & $\begin{array}{c}0.1483^{* * *} \\
(0.0309)\end{array}$ & $\begin{array}{c}0.1073^{* * *} \\
(0.0295)\end{array}$ \\
\hline Exp. fraction of suitable appl. & $\begin{array}{c}0.3606^{* * *} \\
(0.0387)\end{array}$ & $\begin{array}{c}0.2880^{* * *} \\
(0.0459)\end{array}$ \\
\hline year-, region-, occup.-, ind.-FE & yes & yes \\
\hline \multicolumn{3}{|l|}{ Peudo-R ${ }^{2}$} \\
\hline $\mathrm{N}$ & 10,139 & 6,456 \\
\hline
\end{tabular}

Source: German Job Vacancy Survey 2005-2008.

Robust standard errors in brackets. ${ }^{* * *}$ indicates $p<0.01 ; * * p<0.05$; $^{*} p<0.1$.

All these comparative static predictions are based on expected values, i.e., the expected number of applicants coming from the private market and from the PEA, and the expected fraction of suitable applicants coming from the private market and from the PEA. In order to obtain these measures we regress the respective realized measures for the number of (suitable) applicants through the private market and PEA on observable firm- and vacancy characteristics. The respective OLS-regressions can be found in Tables 15 and 16 in the Appendix. ${ }^{16}$ Using the respective predicted values for the expected number of (suitable) applicants coming through the PEA and the private market, we calculate the fraction of suitable applicants coming through the private market and the PEA. The predicted variables are then included into the probit regressions explaining the use of the PEA as search channel as shown in Table 8.

Table 8 shows that the likelihood to register a vacancy with the PEA decreases with the expected number of applicants in the private market and the fraction of suitable applicants coming through the private market. The probability to use the PEA as search channel increases, if the number of applicants and the fraction of suitable applicants among all applicants sent by the PEA increases. Table 17 in the Appendix shows that these results hold for almost all subgroups. This results strongly support our theoretical comparative static predictions.

\footnotetext{
${ }^{16}$ For the regressions on the number of (suitable) applicants through the private market we take all applicants at unregistered vacancies and for registered vacancies only those applicants, who did not come through the PEA. For the number of (suitable) applicants through the PEA we use the information on the number of (suitable) applicants at registered vacancies, who came through the PEA, and take the respective coefficients to predict the number of (suitable) applicants that all registered and unregistered firms.
} 


\section{Conclusion}

Using a unique vacancy dataset, we find that the Public Employment Agency (PEA) distributes workers more evenly among vacancies than the private market. This confirms that the PEA mitigates the coordination frictions present in the job seekers' application process, an aspect, which so far has been neglected in the existing literature. We investigate the implications of having such a market place with lower coordination frictions by using a directed search model, where firms can decide whether to search via the PEA or the private market. Lower coordination frictions in the PEA reduce wage competition among registered firms and enable them to pay lower wages compared to the private market. This advantage has to be traded off against the negative selection of applicants coming through the PEA compared to the private market. We take these (and other) theoretical implications to the data and find strong support for them.

An interesting topic for future research would be to assess the effect of labor market reforms, e.g. the so-called Hartz Reform in Germany, since part of the reform package (Hartz III) aimed at restructuring the Public Employment Agency. To evaluate this effect in the context of the Hartz Reform, it would be necessary to extend the model and data to incorporate other parts of the reform - creating new types of employment opportunities (Hartz I), introducing additional wage subsidies (Hartz II), and cutting unemployment benefits for the long-term unemployed (Hartz IV). We believe our framework will best fit to study this and other related issues like the effect on wage inequality of such a reform policy. 


\section{References}

[1] Acemoglu, D. and R. Shimer, (1999), Holdup and Efficiency with Search Frictions, International Economic Review, 47, 651-699.

[2] Addison, J.T. and P. Portugal, (2002), Job serach methods and outcomes, Oxford Economic Papers, $54,505-533$.

[3] Albrecht, J., Pieter A.G., and S. Vroman, (2006), Equilibrium Directed Search with Multiple Applications, Review of Economic Studies, 73, 869-891.

[4] Albrecht, J., Pieter A.G., and S. Vroman, (2012), A note on Peters and Severinov, Competition among sellers who offer auctions instead of prices, Journal of Economic Theory, 147, 389-392.

[5] Albrecht, J., Pieter A.G., and S. Vroman, (2014), Efficient Entry in Competing Auctions, American Economic Review, forthcoming.

[6] Blau, D.M., and P.K. Robins, (1990), Job search outcomes for the employed and unemployed, Journal of Political Economy, 98 (3), 637-655.

[7] Burdett, K., S. Shi and R. Wright, (2001), Pricing and Matching with Frictions, Journal of Political Economy 109, 1060-1085.

[8] Casella, A., and N. Hanaki, (2008), Information Channels in Labor Markets: One the Resilience of Referral Hiring, Journal of Economic Behabior and Organization 66, 492-513.

[9] Delacroix, A., and S. Shi (2013), Pricing and signaling with frictions, Journal of Economic Theory, $148,1301-1332$.

[10] Fougère, D., J. Pradel, and M. Roger, (2009), Does the public employment service affect search effort and outcomes?, EuroPEAn Economic Review 53, 846-869.

[11] Galenianos, M., (2013), Learning About Match Quality and the Use of Referrals. Review of Economic Dynamics 16, 668-690.

[12] Galenianos, M., (2014), Hiring through Referrals. Journal of Economic Theory 152, 304-323.

[13] Galenianos, M. and P. Kircher, (2009), Directed Search with Multiple Job Applications, Journal of Economic Theory, 114, 445-471.

[14] Gautier, P., B. Hu, and M. Watanabe, (2015), Marketmaking Middlemen, Tinbergen Institute Working paper.

[15] Gregg, P., and J. Wadsworth, (1996), How effective are state employment agencies? Jobcentre use and job matching in Britain, Oxford Bulletin of Economics and Statistics, 58 (3), 442-467.

[16] Guerrieri, V., R. Shimer and R. Wright, (2010), Adverse Selection in Competitive Search Equilibrium, Econometrica, 78, 1823-1862.

[17] Holzer, H.J., (1988), Search method by use by unemployed youth, Journal of Labor Economics,6, $1-20$.

[18] Launov, A., and K. Wälde (2014), The employment effects of reforming a public employment agency, mimeo. 
[19] Masters, A. (2007), Middlemen in Search Equilibrium, International Economic Review, 48, 343362.

[20] McAfee, R. P. (1993), Mechanism Design by Competing Sellers, Econometrica, 61, 1281-1312.

[21] Menzio, G. (2007), A Theory of Partially Directed Search, Journal of Political Economy, 115, 748-769.

[22] Michelacci, C., and J. Suarez (2006), Incomplete Wage Posting, Journal of Political Economy, 114, 1098-1123.

[23] Moen, E. R. , (1997), Competitive Search Equilibrium, Journal of Political Economy, 105, 385-411.

[24] Müller, A., M. Rieben, and M. Stops (2011), Einschaltungspotenzial fr den Arbeitgeber-Service der Bundesagentur für Arbeit: Ergebnisse aus der IAB-Erhebung des Gesamtwirtschaftlichen Stellenangebots, IAB-Stellungnahme, 10, 1-15.

[25] Osberg, L., (1993), Fishing in different pools: Job-search strategies and job finding success in Canada in the Early 1980s, Journal of Labor Economics, 11, 348-386.

[26] Peters, M., (1991), Ex Ante Pricing in Matching Games: Non Steady States, Econometrica, 59, $1425-1454$

[27] Peters, M., (2001), Limits of Exact Equilibria for Capacity Constrained Sellers with Costly Search, Journal of Economic Theory, 95, 139-168.

[28] Peters, M., and S. Severinov (1997), Competition among Sellers who Offer Auctions Instead of Prices, Journal of Economic Theory, 75, 141-179.

[29] Pissarides, C., (1979), Job Matching with State Employment Agencies and Random Search, The Economic Journal, 89, 818-833.

[30] Pollard, E., F. Behling, J. Hillage, and S. Seckesser, (2012), Jobcentre Plus Employer Satisfaction and Experience Survey 2012, Research Reort No 806, Department for Work and Pensions, UK.

[31] Rubinstein, A., and A. Wolinsky. (1987), Middlemen, Quarterly Journal of Economics 102, 581593.

[32] Shi, S., Frictional Assignment I: Effciency, Journal of Economic Theory, 98, 232- 260.

[33] Watanabe, M., (2010), A Model of Merchants, Journal of Economic Theory, 145, 1865-1889.

[34] Watanabe, M., (2013), Middlemen: A Directed Search Equilibrium Approach, Tinbergen Institute Working paper.

[35] Weber, A., and H. Mahringer, (2002), Choice and success of job search methods, Empirical Economics, 35, 153-178.

[36] Wielgosz, J.B., and S. Carpenter (1987), The effectiveness of alternative methods of searching for jobs and finding them: An exploratory analysis of the data bearing upon the ways of coping with joblessness, American Journal of Economics and Sociology, 46 (2), 151-164.

[37] Yavas, A., (1994), Middlemen in Bilateral Search Markets, Journal of Labor Economics 12, No. 3, 406-429. 


\section{A Appendix: Proofs}

\section{A.1 Proof of Lemma 1}

As the number of applicants to a firm $n$ follows a Poisson distribution, Prob. $(n=i)=\frac{x^{i} e^{-x}}{i !}$, given that the probability that a randomly selected applicant is suitable is $\theta \equiv \frac{m+(1-m) \delta^{2}}{m+(1-m) \delta}$, if a productive (or a suitable) worker applies for a firm, then the probability that this worker receives an offer is given by

$$
\begin{aligned}
\eta= & e^{-x}+x e^{-x}\left[\frac{\theta}{2}+1-\theta\right]+\frac{x^{2} e^{-x}}{2}\left[\frac{\theta^{2}}{3}+\frac{2 \theta(1-\theta)}{2}+(1-\theta)^{2}\right]+\ldots \\
+ & \frac{x^{i} e^{-x}}{i !}\left[\theta^{i} \frac{1}{i+1}+i(1-\theta) \theta^{i-1} \frac{1}{i}+\frac{i !}{2 !(i-2) !}(1-\theta)^{2} \theta^{i-2} \frac{1}{i-1}+\ldots\right. \\
& \left.+\frac{i !}{j !(i-j) !}(1-\theta)^{j} \theta^{i-j} \frac{1}{i-j+1}+\ldots+(1-\theta)^{i}\right]+\ldots .
\end{aligned}
$$

To see how it works, consider the case $i=2$ where two other applicants are at the firm, which occurs with probability $\frac{x^{2} e^{-x}}{2}$ (the third term in the above expression). If both of these applicants appear to be suitable at this firm, which happens with probability $\theta^{2}$, then the given applicant will receive an offer with probability $\frac{1}{3}$. If one of them is suitable but the other of them is not, which occurs in 2 ways and with probability $\theta(1-\theta)$, then the given applicant will be offered with probability $\frac{1}{2}$. If none of the other applicants happen to be suitable, which happens with probability $(1-\theta)^{2}$, then the given applicant will be offered with probability one. By induction, the same logic applies to general case with $i$ other applicants (with probability $\frac{x^{i} e^{-x}}{i !}$ ): if $j \leq i$ of the other applicants turn out to be suitable, which comes in $\frac{i !}{j !(i-j) !}$ ways and occurs with probability $\theta^{j}(1-\theta)^{i-j}$, then the given applicant will be offered with probability $\frac{1}{i-j+1}$.

Note that we can simplify the terms,

$$
\begin{aligned}
& \theta^{i} \frac{1}{i+1}+i(1-\theta) \theta^{i-1} \frac{1}{i}+\frac{i !}{2 !(i-2) !}(1-\theta)^{2} \theta^{i-2} \frac{1}{i-1}+\frac{i !}{j !(i-j) !}(1-\theta)^{j} \theta^{i-j} \frac{1}{i-j+1}+\ldots+(1-\theta)^{i} \\
= & \frac{1}{(i+1) \theta} \sum_{j=0}^{i} \frac{(i+1) !}{j !(i+1-j) !}(1-\theta)^{j} \theta^{i+1-j} \\
= & \frac{1}{(i+1) \theta}\left[\sum_{j=0}^{i+1} \frac{(i+1) !}{j !(i+1-j) !}(1-\theta)^{j} \theta^{i+1-j}-(1-\theta)^{i+1}\right] \\
= & \frac{1-(1-\theta)^{i+1}}{(i+1) \theta} .
\end{aligned}
$$

Using this simplification, we have

$$
\eta=\sum_{i=0}^{\infty} \frac{x^{i} e^{-x}}{i !} \frac{1-(1-\theta)^{i+1}}{(i+1) \theta}=\frac{1}{x \theta} \sum_{i=0}^{\infty} \frac{x^{i+1} e^{-x}\left(1-(1-\theta)^{i+1}\right)}{(i+1) !}
$$

Setting $h \equiv i+1$, it is further simplified to

$$
\begin{aligned}
\eta & =\frac{1}{x \theta} \sum_{h=0}^{\infty}\left[\frac{x^{h} e^{-x}}{h !}-\frac{[x(1-\theta)]^{h} e^{-x}}{h !}\right]=\frac{1}{x \theta}\left[1-e^{-x \theta} \sum_{h=0}^{\infty} \frac{[x(1-\theta)]^{h} e^{-x(1-\theta)}}{h !}\right] \\
& =\frac{1-e^{-x \theta}}{x \theta} .
\end{aligned}
$$




\section{A.2 Proof of Lemma 2}

Consider the best deviation as described in the text. Using (4) and (5) simplifies the inequality in question to

$$
\begin{aligned}
\Pi_{a}(\tilde{x})>\Pi_{a}^{\prime} & \Longleftrightarrow m\left(1-c^{m} \eta(\tilde{x})\right)+\delta(1-m)\left(1-c^{u} \delta \eta(\tilde{x})\right)>(m+(1-m) \delta)(1-w) \\
& \Longleftrightarrow-\left(m+\delta^{3}(1-m)\right) \frac{e^{-\tilde{x}}\left(1-e^{-\tilde{x}}\right)}{\tilde{x}}>-(m+\delta(1-m)) \frac{\tilde{x} e^{-\tilde{x}}}{1-e^{-\tilde{x}}}
\end{aligned}
$$

where the last inequality follows from $\frac{\tilde{x}}{1-e^{-\tilde{x}}}>\frac{1-e^{-\tilde{x}}}{\tilde{x}} \Longleftrightarrow 1>\eta(\tilde{x})^{2}$. This completes the proof of Lemma 2.

\section{A.3 Proof of Proposition 1}

Define $\Gamma \equiv \Pi_{s}(\tilde{x})-\Pi_{a}(\tilde{x})$ for $\tilde{x} \in[0, \infty)$, where by $(1)$ and $(5), \tilde{x}=\tilde{x}(\rho)$ is determined by

$$
\frac{e^{-\tilde{x}}}{\tilde{x}}=\frac{v(1-\rho)}{m+(1-m) \delta^{2}} .
$$

This expression shows that $\tilde{x}(\rho)$ is strictly increasing in $\rho \in[0,1)$ and satisfies $\tilde{x}(0) \equiv \underline{\tilde{x}} \in(0, \infty)$ and $\tilde{x}(\rho) \rightarrow \infty$ as $\rho \rightarrow 1$.

In what follows, we use the implicit equation $\Gamma=0$ to show the existence and uniqueness of an equilibrium $\rho \in[0,1)$. There are two possible cases. Suppose in equilibrium $a>v \rho$. This implies $\rho \in[0, \bar{\rho})$ where $\bar{\rho} \equiv \min \left\{\frac{a}{v}, 1\right\}$. Then, $\Gamma=\Gamma(\tilde{x})$ where

$$
\Gamma(\tilde{x})=1-e^{-\tilde{x}}-\tilde{x} e^{-\tilde{x}}-(m+(1-m) \delta)+\left(m+(1-m) \delta^{3}\right) \frac{e^{-\tilde{x}}\left(1-e^{-\tilde{x}}\right)}{\tilde{x}} .
$$

Observe that: $\Gamma(0)=-(1-m) \delta\left(1-\delta^{2}\right)<0 ; \Gamma(\tilde{x}) \rightarrow 1-(m+(1-m) \delta)>0$ as $\tilde{x} \rightarrow \infty$. Hence, since $\Gamma(\tilde{x})$ is continuous in $\tilde{x} \in[0, \infty)$, there exists an $\tilde{x}^{*} \in(0, \infty)$ that satisfies $\Gamma\left(\tilde{x}^{*}\right)=0$. Observe further that $\left.\frac{\partial \Gamma(\tilde{x})}{\partial \tilde{x}}\right|_{\tilde{x}=\tilde{x}^{*}}=$

$$
\begin{aligned}
& =\tilde{x} e^{-\tilde{x}}-\left.\left(m+(1-m) \delta^{3}\right) \frac{e^{-\tilde{x}}}{\tilde{x}^{2}}\left[(\tilde{x}+1)\left(1-e^{-\tilde{x}}\right)-\tilde{x} e^{-\tilde{x}}\right]\right|_{\tilde{x}=\tilde{x}^{*}} \\
& =\frac{\tilde{x}^{*} e^{-\tilde{x}^{*}}}{1-e^{-\tilde{x}^{*}}-\tilde{x}^{*} e^{-\tilde{x}^{*}}}(m+(1-m) \delta) \\
& -\left(m+(1-m) \delta^{3}\right) \frac{\tilde{x}^{*} e^{-\tilde{x}^{*}}}{1-e^{-\tilde{x}^{*}}-\tilde{x}^{*} e^{-\tilde{x}^{*}}}\left[\frac{e^{-\tilde{x}^{*}}\left(1-e^{-\tilde{x}^{*}}\right)}{\tilde{x}^{*}}+\frac{1-e^{-\tilde{x}^{*}}-\tilde{x}^{*} e^{-\tilde{x}^{*}}}{\tilde{x}^{* 3}}\left[\left(\tilde{x}^{*}+1\right)\left(1-e^{-\tilde{x}^{*}}\right)-\tilde{x}^{*} e^{-\tilde{x}^{*}}\right]\right] \\
& >\frac{e^{-\tilde{x}^{*}}}{1-e^{-\tilde{x}^{*}}-\tilde{x}^{*} e^{-\tilde{x}^{*}}}\left[\tilde{x}^{*}-\left(1-\frac{1-e^{-\tilde{x}^{*}}}{\tilde{x}^{*}}\right) e^{-\tilde{x}^{*}}-\left(\frac{1-e^{-\tilde{x}^{*}}}{\tilde{x}^{*}}-e^{-\tilde{x}^{*}}\right)\left(\tilde{x}^{*}+1\right) \frac{1-e^{-\tilde{x}^{*}}}{\tilde{x}^{*}}\right] \\
& =\frac{e^{-\tilde{x}^{*}}}{1-e^{-\tilde{x}^{*}}-\tilde{x}^{*} e^{-\tilde{x}^{*}}}\left[\frac{\left(\tilde{x}^{*}-\left(1-e^{-\tilde{x}^{*}}\right)\right)\left(\tilde{x}^{*}+1-e^{-\tilde{x}^{*}}\right)}{\left.\tilde{x}^{* 2} \tilde{x}^{*}\right)^{2}}\right] \\
& >0 .
\end{aligned}
$$

In the above, we use

$$
\Gamma\left(\tilde{x}^{*}\right)=0 \Leftrightarrow \tilde{x}^{*} e^{-\tilde{x}^{*}}=\frac{\tilde{x}^{*} e^{-\tilde{x}^{*}}}{1-e^{-\tilde{x}^{*}}-\tilde{x}^{*} e^{-\tilde{x}^{*}}}\left[(m+(1-m) \delta)-\left(m+(1-m) \delta^{3}\right) \frac{e^{-\tilde{x}^{*}}\left(1-e^{-\tilde{x}^{*}}\right)}{\tilde{x}^{*}}\right]
$$

in the second equality, and $\tilde{x}+1-e^{-\tilde{x}}>\frac{1-e^{-\tilde{x}}}{\tilde{x}}-e^{-\tilde{x}}$ and $\tilde{x}-\left(1-e^{-\tilde{x}}\right)>1-e^{-\tilde{x}}-\tilde{x} e^{-\tilde{x}}$ in the last inequality. Since $\Gamma(0)<0<\Gamma(\infty), \frac{d \Gamma}{d \tilde{x}}>0$ at $\tilde{x}=\tilde{x}^{*}$ implies $\tilde{x}^{*} \in(0, \infty)$ is unique (that is, $\Gamma(\tilde{x})$ curve cannot cross the line $\Gamma(\tilde{x})=0$ more than once).

Finally, notice that the $\tilde{x}^{*} \in(0, \infty)$ satisfying $\Gamma\left(\tilde{x}^{*}\right)=0$ determined above does not depend on $v$, whereas $\underline{\tilde{x}}(\equiv \tilde{x}(0))$ determined by $(11)$ is strictly decreasing in $v$. Hence, we have $\tilde{x}^{*}>\underline{\tilde{x}} \Leftrightarrow v>v * \equiv$ 
$\left(m+(1-m) \delta^{2}\right) \frac{e^{-\tilde{x}^{*}}}{\tilde{x}^{*}}$. On the other hand, denote by $\overline{\tilde{x}}$ the solution of $\tilde{x}=\tilde{x}(\rho)$ to $(11)$ as $\rho \rightarrow \bar{\rho}$. If $\frac{a}{v} \geq 1$ then $\bar{\rho}=1$ and $\overline{\tilde{x}}=\infty$, so $x^{*}<\overline{\tilde{x}}$. If $\frac{a}{v}<1$ then $\bar{\rho}=\frac{a}{v}<1$ and $\overline{\tilde{x}}<\infty$. In this case, $x^{*}<\overline{\tilde{x}}$ if and only if $v<v^{*}+a$, since by (11),

$$
\frac{e^{-\overline{\tilde{x}}}}{\overline{\tilde{x}}}-\frac{e^{-\tilde{x}^{*}}}{\tilde{x}^{*}}=\frac{1}{m+(1-m) \delta^{2}}\left(v\left(1-\frac{a}{v}\right)-v^{*}\right)=\frac{1}{m+(1-m) \delta^{2}}\left(v-a-v^{*}\right),
$$

which implies

$$
x^{*}<\overline{\tilde{x}} \Longleftrightarrow \frac{e^{-\overline{\tilde{x}}}}{\overline{\tilde{x}}}<\frac{e^{-x^{*}}}{x^{*}} \Longleftrightarrow v<v^{*}+a .
$$

To sum up, there exists a unique $\rho \in(0, \bar{\rho})$ that satisfies $\frac{e^{-\tilde{x}^{*}}}{\tilde{x}^{*}}=\frac{v(1-\rho)}{m+(1-m) \delta^{2}}$ and $\left.\Pi_{s}\left(\tilde{x}^{*}\right)=\Pi_{a}\left(\tilde{x}^{*}\right)\right)$ if and only if $v \in\left(v^{*}, v^{*}+a\right)$, and $\rho=0$, satisfying $\Pi_{s}\left(\tilde{x}^{*}\right)>\Pi_{a}\left(\tilde{x}^{*}\right)$, if and only if $v \in\left(0, v^{*}\right)$

Suppose next in equilibrium $a \leq v \rho$. This implies $\rho \in[\bar{\rho}, 1)$, where $\bar{\rho} \equiv \min \left\{\frac{a}{v}, 1\right\}$, and is possible only when $\frac{a}{v}<1$. Then, $\Gamma=\Gamma(\rho, \tilde{x})$ where

$$
\Gamma(\rho, \tilde{x})=1-e^{-\tilde{x}}-\tilde{x} e^{-\tilde{x}}-\frac{a}{\rho v}\left[(m+(1-m) \delta)-\left(m+(1-m) \delta^{3}\right) \frac{e^{-\tilde{x}}\left(1-e^{-\tilde{x}}\right)}{\tilde{x}}\right],
$$

where $\tilde{x}=\tilde{x}(\rho)$ is determined by (11) as before. Observe that:

$$
\Gamma(\bar{\rho}, \overline{\tilde{x}})=1-e^{-\tilde{x}}-\tilde{x} e^{-\tilde{x}}-\left[(m+(1-m) \delta)-\left(m+(1-m) \delta^{3}\right) \frac{e^{-\tilde{x}}\left(1-e^{-\tilde{x}}\right)}{\tilde{x}}\right] \leq 0,
$$

if and only if $v \geq v^{*}+a$ (see above that $\Gamma(\bar{\rho}, \overline{\tilde{x}})=\Gamma(\overline{\tilde{x}})<0$ for $\left.v \geq v^{*}+a\right) ; \Gamma(\rho, \tilde{x}) \rightarrow 1-\frac{a}{v}(m+(1-$ $m) \delta)>0$ as $\rho \rightarrow 1$. Hence, since $\Gamma(\cdot)$ is continuous in $\rho \in[\bar{\rho}, 1)$, there exists a $\rho^{*} \in[\bar{\rho}, 1)$ that satisfies $\Gamma\left(\rho^{*}, \tilde{x}\left(\rho^{*}\right)\right)=0$ if and only if $v \geq v^{*}+a$. Observe further that

$$
\left.\frac{d \Gamma(\cdot)}{d \rho}\right|_{\rho=\rho^{*}}=\frac{\partial \Gamma(\cdot)}{\partial \rho}+\left.\frac{d \tilde{x}}{d \rho} \frac{\partial \Gamma(\cdot)}{\partial x}\right|_{\rho=\rho^{*}}
$$

where $\frac{\partial \Gamma(\cdot)}{\partial \rho}=\frac{a}{\rho^{2} v}\left[m+(1-m) \delta-\left(m+(1-m) \delta^{3}\right) \frac{e^{-\tilde{x}}\left(1-e^{-\tilde{x}}\right)}{\tilde{x}}\right]>0, \frac{d \tilde{x}}{d \rho}>0$ (by $\left.(11)\right)$, and

$$
\left.\frac{\partial \Gamma(\cdot)}{\partial \tilde{x}}\right|_{\rho=\rho^{*}}>\left.\frac{a}{\rho v} \frac{e^{-\tilde{x}}}{1-e^{-\tilde{x}}-\tilde{x} e^{-\tilde{x}}}\left[\frac{\left(\tilde{x}-\left(1-e^{-\tilde{x}}\right)\right)\left(\tilde{x}+1-e^{-\tilde{x}}\right)}{\tilde{x}}-\frac{\left(1-e^{-\tilde{x}}-\tilde{x} e^{-\tilde{x}}\right)^{2}}{\tilde{x}}\right]\right|_{\rho=\rho^{*}}>0,
$$

which follows from exactly the procedure developed above to show $\left.\frac{\partial \Gamma(x)}{d \tilde{x}}\right|_{\tilde{x}=\tilde{x}^{*}}>0$ in (12). Therefore, $\rho^{*} \in[\bar{\rho}, 1)$ that satisfies $\Gamma\left(\rho^{*}, \tilde{x}\left(\rho^{*}\right)\right)=0$ is unique given $v \geq v^{*}+a$.

Combining with the previous result, we have shown that there exist a unique $\rho \in(0,1)$ if and only if $v>v^{*}$, and $\rho=0$ if and only if $v \leq v^{*}$. This completes the proof of Proposition 1 .

\section{A.4 Proof of Corollary 1}

The inequality follows immediately by applying $c^{n}=e^{-\tilde{x}}$ and $c^{d}=\delta e^{-\tilde{x}}$. This completes the proof of Corollary 1.

\section{A.5 Proof of Corollary 2 and 3}

In text. 


\section{A.6 Proof of Proposition 2}

$\odot \underline{\tilde{x} \text { increases in } m(\text { or } \delta)}$ : Consider first the case $a>\rho v$. Then, with $\Gamma=\Gamma\left(\tilde{x}^{*}\right)=0$ in $(12)$, we have

$$
\begin{aligned}
\left.\frac{\partial \Gamma}{\partial m}\right|_{\tilde{x}=\tilde{x}^{*}} & =-(1-\delta)+\left.\left(1-\delta^{3}\right) \frac{e^{-\tilde{x}}\left(1-e^{-\tilde{x}}\right)}{\tilde{x}}\right|_{\tilde{x}=\tilde{x}^{*}} \\
& =\frac{1-\delta}{m+(1-m) \delta^{3}}\left[-\left(1+\delta+\delta^{2}\right)\left(1-e^{-\tilde{x}^{*}}-\tilde{x}^{*} e^{-\tilde{x}^{*}}\right)+\delta(1+\delta)(1-(1-\delta) m)\right] \\
& \equiv \frac{1-\delta}{m+(1-m) \delta^{3}} \Upsilon(m)
\end{aligned}
$$

In what follows, we show that $\Upsilon(m)<$ for all $m \in(0,1)$. Now, let $y(x) \equiv 1-e^{-x}-x e^{-x}$. Then, observe that

$$
1-y(x)=e^{-x}(1+x)>\frac{e^{-x}\left(1-e^{-x}\right)}{x}
$$

for all $x \in(0, \infty)$. This implies that

$$
\begin{aligned}
\Gamma\left(\tilde{x}^{*}\right) & =y\left(\tilde{x}^{*}\right)-(m+(1-m) \delta)+\left(m+(1-m) \delta^{3}\right) \frac{e^{-\tilde{x}^{*}}\left(1-e^{-\tilde{x}^{*}}\right)}{\tilde{x}^{*}} \\
& <y\left(\tilde{x}^{*}\right)-(m+(1-m) \delta)+\left(m+(1-m) \delta^{3}\right)\left(1-y\left(\tilde{x}^{*}\right)\right) .
\end{aligned}
$$

Since $\Gamma\left(\tilde{x}^{*}\right)=0$, the latter inequality further implies that

$$
y\left(\tilde{x}^{*}\right)>\frac{\delta(1+\delta)}{1+\delta+\delta^{2}}
$$

Applying this relationship into $\Upsilon(m)$, we have:

$$
\Upsilon(m) \equiv-\left(1+\delta+\delta^{2}\right)\left(1-e^{-\tilde{x}^{*}}-\tilde{x}^{*} e^{-\tilde{x}^{*}}\right)+\delta(1+\delta)(1-(1-\delta) m)<0
$$

for all $m \in(0,1)$. Hence, $\left.\frac{\partial \Gamma}{\partial m}\right|_{\tilde{x}=\tilde{x}^{*}}<0$ and, since $\left.\frac{\partial \Gamma}{\partial \tilde{x}}\right|_{\tilde{x}=\tilde{x}^{*}}>0$, it follows that $\frac{d \tilde{x}^{*}}{d m}>0$. A similar procedure applies to get $\left.\frac{\partial \Gamma}{\partial \delta}\right|_{\tilde{x}=\tilde{x}^{*}}<0$ and therefore $\frac{d \tilde{x}^{*}}{d \delta}>0$. Note finally that $\Gamma(\tilde{x})$ is independent of $a(>\rho v)$ and so changes in $a$ do not affect $\tilde{x}^{*}$.

Consider next the case $a \leq \rho v$. We follow the same steps as established above. With $\Gamma=\Gamma(\rho, \tilde{x})=0$ in (13), we have

$$
\begin{aligned}
\left.\frac{\partial \Gamma}{\partial m}\right|_{\rho=\rho^{*}} & =\left.\frac{a}{\rho v}\left[-(1-\delta)+\left(1-\delta^{3}\right) \frac{e^{-\tilde{x}}\left(1-e^{-\tilde{x}}\right)}{\tilde{x}}\right]\right|_{\rho=\rho^{*}} \\
& =\frac{1-\delta}{m+(1-m) \delta^{3}}\left[-\frac{a}{\rho^{*} v}\left(1+\delta+\delta^{2}\right)\left(1-e^{-\tilde{x}^{*}}-\tilde{x}^{*} e^{-\tilde{x}^{*}}\right)+\delta(1+\delta)(1-(1-\delta) m)\right] \\
& \equiv \frac{1-\delta}{m+(1-m) \delta^{3}} \tilde{\Upsilon}(m) .
\end{aligned}
$$

As before, with $y(x) \equiv 1-e^{-x}-x e^{-x}<1-\frac{e^{-x}\left(1-e^{-x}\right)}{x}$, we notice that

$$
\begin{aligned}
\Gamma\left(\rho^{*}, \tilde{x}^{*}\right) & =y\left(\tilde{x}^{*}\right)-\frac{a}{\rho^{*} v}\left[(m+(1-m) \delta)-\left(m+(1-m) \delta^{3}\right) \frac{e^{-\tilde{x}^{*}}\left(1-e^{-\tilde{x}^{*}}\right)}{\tilde{x}^{*}}\right] \\
& <y\left(\tilde{x}^{*}\right)-\frac{a}{\rho^{*} v}\left[(m+(1-m) \delta)-\left(m+(1-m) \delta^{3}\right)\left(1-y\left(\tilde{x}^{*}\right)\right)\right] .
\end{aligned}
$$

Since $\Gamma\left(\rho^{*}, \tilde{x}^{*}\right)=0$, we have

$$
y\left(\tilde{x}^{*}\right)>\frac{\frac{a}{\rho^{*} v}(1-m) \delta\left(1-\delta^{2}\right)}{1-\frac{a}{\rho^{*} v}\left(m+(1-m) \delta^{3}\right)},
$$


which further implies

$$
\tilde{\Upsilon}(m) \equiv-\frac{a}{\rho^{*} v}\left(1+\delta+\delta^{2}\right)\left(1-e^{-\tilde{x}^{*}}-\tilde{x}^{*} e^{-\tilde{x}^{*}}\right)+\delta(1+\delta)(1-(1-\delta) m)<0
$$

for all $m \in(0,1)$. Hence, $\left.\frac{\partial \Gamma}{\partial m}\right|_{\rho=\rho^{*}}<0$ and, since $\left.\frac{\partial \Gamma}{\partial \rho}\right|_{\rho=\rho^{*}}>0$, it follows that $\frac{d \rho^{*}}{d m}>0$.

Now, with $\rho=\rho^{*}$, denote by $\xi\left(m, \rho^{*}(m)\right)$ the R.H.S. of (11). Then, we have

$$
\frac{d \xi(\cdot)}{d m}=\frac{\partial \xi(\cdot)}{\partial m}+\frac{d \rho^{*}}{d m} \frac{\partial \xi(\cdot)}{\partial \rho^{*}}<0,
$$

since $\frac{\partial \xi(\cdot)}{\partial \rho^{*}}<0, \frac{d \rho^{*}}{d m}>0$ (as shown above), and

$$
\frac{\partial \xi(\cdot)}{\partial m}=-\frac{v\left(1-\rho^{*}\right)}{m^{2}[m+(1-m) \delta]^{2}}\left\{\delta^{2}[m+(1-m) \delta]+m(1-\delta)\left[m+(1-m) \delta^{2}\right]\right\}<0 .
$$

Then, because the L.H.S. of (11) is strictly decreasing in $\tilde{x}$, this implies that $\left.\frac{d \tilde{x}}{d m}\right|_{\rho=\rho^{*}}>0$.

A similar procedure applies to get $\left.\frac{\partial \Gamma}{\partial \delta}\right|_{\tilde{x}=\tilde{x}^{*}}<0$ and therefore $\frac{d \rho^{*}}{d \delta}>0$ and $\frac{d \tilde{x}^{*}}{d \delta}>0$.

$\odot \underline{\tilde{x} \text { increases in } a}:\left.\frac{d \tilde{x}}{d a}\right|_{\rho=\rho^{*}}>0$ follows from $\frac{\partial \Gamma}{\partial a}<0$, and hence $\frac{d \rho^{*}}{d a}>0$.

\section{A.7 Proof of Proposition 3}

Consider the case $a>\rho v$. Now the fixed point condition, $\Gamma \equiv \Pi_{s}(\tilde{x})-\Pi_{a}(\tilde{x})=0$, is modified to

$$
\Gamma(\tilde{x})=1-e^{-\tilde{x}}-\tilde{x} e^{-\tilde{x}}-(m+(1-m) \delta)+\left(m+(1-m) \delta^{3}\right) \frac{e^{-\tilde{x}}\left(1-e^{-\tilde{x}}\right)}{\tilde{x}}+f .
$$

Define $\bar{f} \equiv(1-m) \delta\left(1-\delta^{2}\right)$. Observe that for $f<\bar{f}: \Gamma(0)=-(1-m) \delta\left(1-\delta^{2}\right)+f<0 ; \Gamma(\tilde{x}) \rightarrow$ $1-(m+(1-m) \delta)+f>0$ as $\tilde{x} \rightarrow \infty$. Hence, since $\Gamma(\tilde{x})$ is continuous in $\tilde{x} \in[0, \infty)$, there exists an $\tilde{x}^{*} \in(0, \infty)$ that satisfies $\Gamma\left(\tilde{x}^{*}\right)=0$ for $f<\bar{f}$. The procedure to show $\left.\frac{\partial \Gamma(\tilde{x})}{\partial \tilde{x}}\right|_{\tilde{x}=\tilde{x}^{*}}>0$ is identical to the previous analysis. Hence, we have a continuous function $\tilde{x}=\tilde{x}(f)$. Applying this function to

$$
\tilde{x}=\frac{m+(1-m) \delta^{2}}{v(1-\rho)}\left(e^{-\tilde{x}}-\frac{f}{\theta}\right),
$$

shows that there exists a subset of $f \in(0, \bar{f})$ that guarantees that $\tilde{x} \in(0, \infty)$ and $\rho \in(0,1)$. A similar steps apply to the other case $a \leq \rho v$. This completes the proof of Proposition 3 .

\section{A.8 Proof of Proposition 4}

Given the equilibrium value $\rho^{*} \in(0,1)\left(\right.$ or $\left.\rho^{*}=0\right)$ determined by $\Pi_{s}(\tilde{x})=\Pi_{a}(\tilde{x})\left(\right.$ or $\left.\Pi_{s}(\tilde{x})>\Pi_{a}(\tilde{x})\right)$ with $\tilde{x}=\tilde{x}(\rho)$, the free entry condition

$$
\Pi_{s}(\tilde{x})=1-e^{-\tilde{x}}-\tilde{x} e^{-\tilde{x}}=K
$$

determines a unique value of $\tilde{x} \in(0, \infty)$ and hence $v \in(0, \infty)$. Given Proposition 1 , this establishes the existence of free entry equilibrium with active search markets. This completes the proof of Proposition 4. 


\section{A.9 Proof of Proposition 5}

Consider the case (9) holds true and the profit of using the PEA is given by (10). Then, for $\frac{a}{v \rho} \geq 1$, we have

$$
\Gamma(\tilde{x}) \equiv \Pi_{a}(\tilde{x})-\Pi_{s}(\tilde{x})=1-\frac{e^{-\tilde{x}}\left(1-e^{-\tilde{x}}\right)}{\tilde{x}}-\left(1-e^{-\tilde{x}}-\tilde{x} e^{-\tilde{x}}\right)>0
$$

for all $\tilde{x} \in(0, \infty)$. Hence, if $\frac{a}{v} \geq 1$ then $\rho=1$. For $\frac{a}{v \rho}<1$, we have

$$
\Gamma(\tilde{x}(\rho), \rho) \equiv \Pi_{a}(\tilde{x})-\Pi_{s}(\tilde{x})=\frac{a}{v \rho}\left(1-\frac{e^{-\tilde{x}}\left(1-e^{-\tilde{x}}\right)}{\tilde{x}}\right)-\left(1-e^{-\tilde{x}}-\tilde{x} e^{-\tilde{x}}\right),
$$

which satisfies: $\Gamma(\tilde{x}(\bar{\rho}), \bar{\rho})=1-\frac{e^{-\tilde{x}}\left(1-e^{-\tilde{x}}\right)}{\tilde{x}}-\left(1-e^{-\tilde{x}}-\tilde{x} e^{-\tilde{x}}\right)>0$ with $\bar{\rho}=\frac{a}{v}<1 ; \Gamma(\tilde{x}(\bar{\rho}), \bar{\rho}) \rightarrow$ $\frac{a}{v}-1<0$ as $\rho \rightarrow 1$. Hence, if $\frac{a}{v}<1$ then $\rho \in(\bar{\rho}, 1)$.

Consider next the case (9) does not hold true. Then, the profit to be registered in the PEA is modified to:

$$
\Pi_{a}(\tilde{x})=m\left(1-c^{m} \eta(\tilde{x})\right)+\left(\min \left\{\frac{a}{\rho v}, 1\right\}-m\right) \delta\left(1-c^{u} \delta \eta(\tilde{x})\right) .
$$

For $\frac{a}{\rho v} \leq 1$, the analysis is identical to the one we offered before, where we have shown that there exists a unique $\rho \in(0, \bar{\rho})$ if and only if $v \in\left(v^{*}, v^{*}+a\right)$, and $\rho=0$ if and only if $v \in\left(0, v^{*}\right)$. For $\frac{a}{\rho v}>1$, we define $\Gamma(\tilde{x}, \rho)=\Pi_{s}-\Pi_{a}$

$$
=1-e^{-\tilde{x}}-\tilde{x} e^{-\tilde{x}}-\left[\left(m+\left(\frac{a}{\rho v}-m\right) \delta\right)-\left(m+\left(\frac{a}{\rho v}-m\right) \delta^{3}\right) \frac{e^{-\tilde{x}}\left(1-e^{-\tilde{x}}\right)}{\tilde{x}}\right],
$$

where $\tilde{x}=\tilde{x}(\rho)$ is determined by (11) as before. Observe that:

$$
\Gamma(\overline{\tilde{x}}, \bar{\rho})=1-e^{-\tilde{x}}-\tilde{x} e^{-\tilde{x}}-\left[(m+(1-m) \delta)-\left(m+(1-m) \delta^{3}\right) \frac{e^{-\tilde{x}}\left(1-e^{-\tilde{x}}\right)}{\tilde{x}}\right] \leq 0,
$$

if and only if $v \geq v^{*}+a$ (as shown in the proof of Proposition 1$) ; \Gamma(\tilde{x}, \rho) \rightarrow 1-\left(m+\left(\frac{a}{v}-m\right) \delta\right)>0$ as $\rho \rightarrow 1$. Hence, $\rho \in[\bar{\rho}, 1)$ if and only if $v \geq v^{*}+a$.

To sum, when (9) does not hold true, we must have $\rho \in[0,1)$ for any parameter values. Therefore, $\rho=1$ if and only if (9) holds true and $\frac{a}{v} \geq 1$, or equivalently $\rho=1$ if and only if $\min \{a, m\} \geq v$. This completes the proof of Proposition 5. 


\section{B Appendix: Tables}

Table 9: PEA used as search and hiring channel (descriptive statistics)

\begin{tabular}{lcc}
\hline \hline & $\begin{array}{c}\text { Fraction of vacancies (in \%) } \\
\text { search channel }\end{array}$ & $\begin{array}{c}\text { using PE as } \\
\text { hiring channel }\end{array}$ \\
\hline \hline all vacancies & 48.3 & 17.3 \\
low qualification & 60.9 & 17.7 \\
medium qualification & 50.3 & 20.7 \\
high qualification & 31.9 & 5.7 \\
occupation specific experience & 47.8 & 16.4 \\
no occupation specific experience & 48.7 & 18.1 \\
permanent & 46.3 & 14.6 \\
temporary & 51.2 & 21.2 \\
full-time & 48.2 & 15.9 \\
part-time & 47.4 & 23.8 \\
weekend-work & 50.6 & 16.8 \\
no weekend-work & 48.4 & 17.9 \\
firm size (1 - 19) & 53.1 & 22.7 \\
firm size (20 - 49) & 46.6 & 18.6 \\
firm size (50 - 199) & 50.2 & 20.2 \\
firm size (200 - 499) & 46.3 & 14.6 \\
firm size (500 +) & 43.8 & 9.6 \\
\hline \hline
\end{tabular}

Source: German Job Vacancy Survey 2005-2008.

Weighted averages using sampling weights. 
Table 10: Differences in the variances of the number of applicants between PEA and private market for different subgroups

\begin{tabular}{|c|c|c|}
\hline & $\begin{array}{c}\text { total variance } \\
\text { F-statistic }=\text { ratio } \\
(1)\end{array}$ & $\begin{array}{c}\text { residual variance } \\
\text { F-statistic }=\text { ratio } \\
(2)\end{array}$ \\
\hline & \multicolumn{2}{|c|}{ full sample } \\
\hline low qualification & $\mathrm{F}(558,558)=1.3197^{* * *}$ & $\mathrm{~F}(382,381)=1.1345$ \\
\hline medium qualification & $\mathrm{F}(4248,4248)=1.9874^{* * *}$ & $\mathrm{~F}(3125,3115)=1.5036^{* * *}$ \\
\hline high qualification & $\mathrm{F}(1004,1004)=1.7812^{* * *}$ & $\mathrm{~F}(761,761)=1.1753^{* *}$ \\
\hline occupation specific exp. (yes) & $\mathrm{F}(2924,2924)=1.9694^{* * *}$ & $\mathrm{~F}(2078,2069)=1.3966^{* * *}$ \\
\hline occupation specific exp. (no) & $\mathrm{F}(3059,3059)=1.9102^{* * *}$ & $\mathrm{~F}(2191,2189)=1.3416^{* * *}$ \\
\hline permanent & $\mathrm{F}(2902,2902)=1.8124^{* * *}$ & $\mathrm{~F}(2078,2076)=1.2173^{* * *}$ \\
\hline temporary & $\mathrm{F}(2991,2991)=2.0401^{* * *}$ & $\mathrm{~F}(2191,2182)=1.5348^{* * *}$ \\
\hline full-time & $\mathrm{F}(4861,4861)=1.9295^{* * *}$ & $\mathrm{~F}(3481,3471)=1.3222^{* * *}$ \\
\hline part-time & $\mathrm{F}(1067,1067)=2.0149^{* * *}$ & $\mathrm{~F}(788,787)=1.6108^{* * *}$ \\
\hline weekend-work (yes) & $\mathrm{F}(824,824)=1.4287^{* * *}$ & $\mathrm{~F}(722,722)=1.1911^{* * *}$ \\
\hline weekend-work (no) & $\mathrm{F}(4022,4022)=2.0253^{* * *}$ & $\mathrm{~F}(3547,3536)=1.4075^{* * *}$ \\
\hline firm size $(1-19)$ & $\mathrm{F}(1964,1964)=1.6926^{* * *}$ & $\mathrm{~F}(1281,1281)=1.3261^{* * *}$ \\
\hline firm size $(20-49)$ & $\mathrm{F}(1475,1475)=1.9951^{* * *}$ & $\mathrm{~F}(1036,1032)=1.3279^{* * *}$ \\
\hline firm size $(50-199)$ & $\mathrm{F}(1317,1317)=1.8915^{* * *}$ & $\mathrm{~F}(987,981)=1.3476^{* * *}$ \\
\hline firm size $(200-499)$ & $\mathrm{F}(636,636)=1.8230^{* * *}$ & $\mathrm{~F}(501,500)=1.8338^{* * *}$ \\
\hline \multirow[t]{2}{*}{ firm size $(500+)$} & $\mathrm{F}(588,588)=1.6417^{* * *}$ & $\mathrm{~F}(461,461)=1.2003^{* *}$ \\
\hline & \multicolumn{2}{|c|}{ restricted sample } \\
\hline low qualification & $\mathrm{F}(294,294)=1.3744^{* * *}$ & $\mathrm{~F}(207,214)=1.1097$ \\
\hline medium qualification & $\mathrm{F}(2411,2411)=2.1172^{* * *}$ & $\mathrm{~F}(1814,1822)=1.3139^{* * *}$ \\
\hline high qualification & $\mathrm{F}(595,595)=2.0228^{* * *}$ & $\mathrm{~F}(437,442)=0.9962$ \\
\hline occupation specific exp. (yes) & $\mathrm{F}(1611,1611)=2.1411^{* * *}$ & $\mathrm{~F}(1168,1179)=1.1890^{* * *}$ \\
\hline occupation specific exp. (no) & $\mathrm{F}(1771,1771)=2.0464^{* * *}$ & $\mathrm{~F}(1291,1300)=1.2656^{* * *}$ \\
\hline permanent & $\mathrm{F}(1544,1544)=1.9063^{* * *}$ & $\mathrm{~F}(1125,1138)=1.1609^{* * *}$ \\
\hline temporary & $\mathrm{F}(1794,1794)=2.2339 * * *$ & $\mathrm{~F}(1334,1341)=1.2980^{* * *}$ \\
\hline full-time & $\mathrm{F}(2664,2664)=2.0780^{* * *}$ & $\mathrm{~F}(1944,1962)=1.1707^{* * *}$ \\
\hline part-time & $\mathrm{F}(693,693)=2.1757^{* * *}$ & $\mathrm{~F}(515,517)=1.5525^{* * *}$ \\
\hline weekend-work (yes) & $\mathrm{F}(467,467)=1.4644^{* * *}$ & $\mathrm{~F}(417,421)=1.3673^{* * *}$ \\
\hline weekend-work (no) & $\mathrm{F}(2320,2320)=2.2233^{* * *}$ & $\mathrm{~F}(2042,2058)=1.2072^{* * *}$ \\
\hline firm size $(1-19)$ & $\mathrm{F}(1055,1055)=1.8341^{* * *}$ & $\mathrm{~F}(710,714)=1.3912^{* * *}$ \\
\hline firm size $(20-49)$ & $\mathrm{F}(810,810)=2.2723^{* * *}$ & $\mathrm{~F}(590,596)=1.0540$ \\
\hline firm size $(50-199)$ & $\mathrm{F}(783,783)=2.0865^{* * *}$ & $\mathrm{~F}(594,599)=1.2144^{* * *}$ \\
\hline firm size $(200-499)$ & $\mathrm{F}(391,391)=1.9411^{* * *}$ & $\mathrm{~F}(299,302)=1.3437^{* * *}$ \\
\hline firm size $(500+)$ & $\mathrm{F}(340,340)=1.7530^{* * *}$ & $\mathrm{~F}(263,265)=1.1960^{*}$ \\
\hline
\end{tabular}

Source: German Job Vacancy Survey 2005-2008, restricted sample.

Variance-Ratio-Test: $\mathrm{H}_{0}:$ Ratio $=1{ }^{* * *}$ indicates $p<0.01$; ${ }^{*} p<0.05 ;{ }^{*} p<0.1$.

Residual variances of the (log) number of applicants are based on column (3) and (4) in Table 2. 
Table 11: Differences in the fraction of suitable workers for different subgroups

\begin{tabular}{|c|c|c|c|c|}
\hline & \multicolumn{4}{|c|}{ Differences in the fraction of suitable workers } \\
\hline & \multicolumn{2}{|c|}{ full sample } & \multicolumn{2}{|c|}{ restricted sample } \\
\hline & $(1)$ & $(2)$ & $(3)$ & $(4)$ \\
\hline low qualification & $-0.0438^{* *}$ & $(0.0334)$ & -0.0260 & $(0.0452)$ \\
\hline medium qualification & $-0.0577 * * *$ & $(0.0095)$ & $-0.0300 * * *$ & $(0.0128)$ \\
\hline high qualification & -0.0090 & $(0.0192)$ & 0.0049 & $(0.0247)$ \\
\hline occupation specific exp. (yes) & $-0.0460 * * *$ & $(0.0116)$ & $-0.0325^{* *}$ & $(0.0157)$ \\
\hline occupation specific exp. (no) & $-0.0496^{* * *}$ & $(0.0114)$ & -0.0121 & $(0.0152)$ \\
\hline permanent & $-0.0737^{* * *}$ & $(0.0112)$ & $-0.0657^{* * *}$ & $(0.0152)$ \\
\hline temporary & $-0.0211^{* *}$ & $(0.0121)$ & 0.0196 & $(0.0158)$ \\
\hline full-time & $-0.0527^{* * *}$ & $(0.0091)$ & $-0.0280^{* *}$ & $(0.0125)$ \\
\hline part-time & $-0.0255^{*}$ & $(0.0193)$ & -0.0016 & $(0.0232)$ \\
\hline weekend-work (yes) & $-0.0918^{* * *}$ & $(0.0228)$ & $-0.0850 * * *$ & $(0.0293)$ \\
\hline weekend-work (no) & $-0.0447^{* * *}$ & $(0.0098)$ & $-0.0173^{*}$ & $(0.0131)$ \\
\hline firm size $(1-19)$ & $-0.0770 * * *$ & $(0.0159)$ & $-0.0393^{* *}$ & $(0.0225)$ \\
\hline firm size $(20-49)$ & $-0.0676^{* * *}$ & $(0.0173)$ & $-0.0467^{* *}$ & $(0.0237)$ \\
\hline firm size $(50-199)$ & $-0.0499 * * *$ & $(0.0162)$ & $-0.0416^{* *}$ & $(0.0206)$ \\
\hline firm size $(200-499)$ & -0.0137 & $(0.0216)$ & 0.0085 & $(0.0278)$ \\
\hline firm size $(500+)$ & 0.0506 & $(0.0212)$ & 0.0831 & $(0.0271)$ \\
\hline
\end{tabular}

Source: German Job Vacancy Survey 2005-2008.

Robust standard errors in brackets. ${ }^{* * *}$ indicates $p<0.01$; ${ }^{* *} p<0.05 ; * p<0.1$. 
Table 12: Characteristics of hired workers

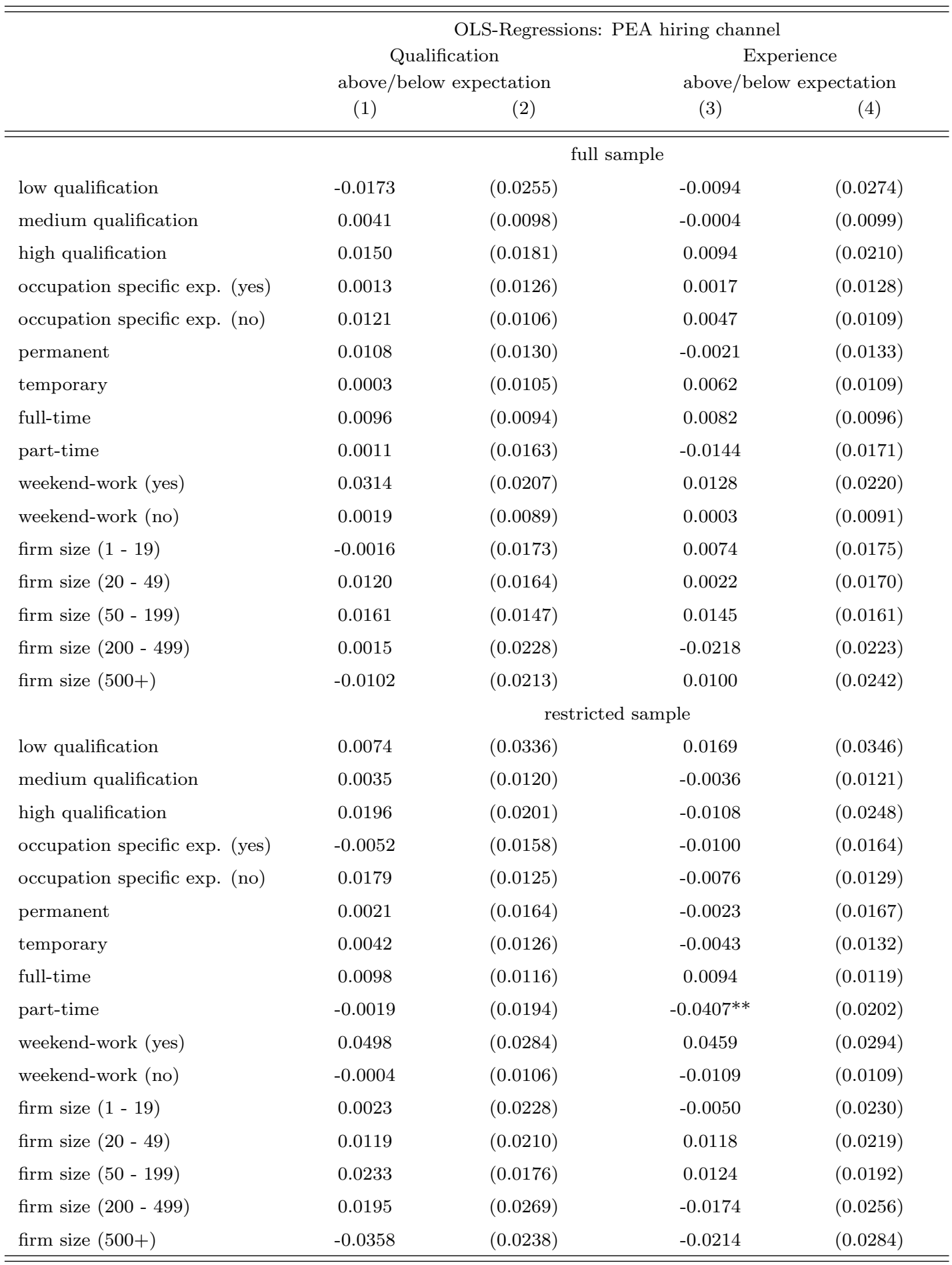

Source: German Job Vacancy Survey 2005-2008.

Robust standard errors in brackets. ${ }^{* * *}$ indicates $p<0.01 ;{ }^{* *} p<0.05 ;{ }^{*} p<0.1$.

NA: The number of observations was too small. 
Table 13: Wage difference between registered and unregistered jobs for different subgroups

\begin{tabular}{|c|c|c|c|c|}
\hline & \multicolumn{4}{|c|}{ OLS-Regressions } \\
\hline & \multicolumn{2}{|c|}{ PEA search channel } & \multicolumn{2}{|c|}{ PEA hiring channel } \\
\hline & (1) & $(2)$ & (3) & $(4)$ \\
\hline & \multicolumn{4}{|c|}{ full sample } \\
\hline low qualification & -0.0382 & $(0.0329)$ & -0.0181 & $(0.0439)$ \\
\hline medium qualification & $-0.0231^{* * *}$ & $(0.0086)$ & -0.0168 & $(0.0127)$ \\
\hline high qualification & -0.0367 & $(0.0290)$ & -0.0594 & $(0.0447)$ \\
\hline occupation specific exp. (yes) & $-0.0316^{*}$ & $(0.0171)$ & $-0.0628^{* *}$ & $(0.0267)$ \\
\hline occupation specific exp. (no) & $-0.0247^{* * *}$ & $(0.0089)$ & -0.0138 & $(0.0126)$ \\
\hline permanent & $-0.0302^{* * *}$ & $(0.0099)$ & $-0.0323^{* *}$ & $(0.0155)$ \\
\hline temporary & $-0.0288^{* *}$ & $(0.0138)$ & -0.0055 & $(0.0181)$ \\
\hline full-time & $-0.0266^{* * *}$ & $(0.0070)$ & $-0.0327^{* * *}$ & $(0.0102)$ \\
\hline part-time & -0.0196 & $(0.0783)$ & 0.0704 & $(0.1168)$ \\
\hline weekend-work (yes) & 0.0303 & $(0.0204)$ & 0.0029 & $(0.0272)$ \\
\hline weekend-work (no) & $-0.0300^{* * *}$ & $(0.0085)$ & $-0.0285^{* *}$ & $(0.0123)$ \\
\hline firm size $(1-19)$ & -0.0191 & $(0.0181)$ & -0.0152 & $(0.0246)$ \\
\hline firm size $(20-49)$ & $-0.0413^{* * *}$ & $(0.0156)$ & -0.0031 & $(0.0196)$ \\
\hline firm size $(50-199)$ & $-0.0498^{* * *}$ & $(0.0182)$ & -0.0060 & $(0.0273)$ \\
\hline firm size $(200-499)$ & 0.0411 & $(0.0717)$ & 0.0469 & $(0.1462)$ \\
\hline \multirow[t]{2}{*}{ firm size $(500+)$} & 0.0018 & $(0.1042)$ & 0.0039 & $(0.2257)$ \\
\hline & \multicolumn{4}{|c|}{ restricted sample } \\
\hline low qualification & -0.0253 & $(0.1300)$ & 0.0163 & $(0.1823)$ \\
\hline medium qualification & $-0.0421^{* * *}$ & $(0.0146)$ & -0.0279 & $(0.0228)$ \\
\hline high qualification & -0.0540 & $(0.0615)$ & -0.0659 & $(0.0931)$ \\
\hline occupation specific exp. (yes) & -0.0490 & $(0.0371)$ & -0.0763 & $(0.0551)$ \\
\hline occupation specific exp. (no) & $-0.0383^{* *}$ & $(0.0160)$ & -0.0225 & $(0.0227)$ \\
\hline permanent & $-0.0540^{* * *}$ & $(0.0177)$ & -0.0169 & $(0.0279)$ \\
\hline temporary & -0.0342 & $(0.0279)$ & -0.0115 & $(0.0403)$ \\
\hline full-time & $0.0389^{* * *}$ & $(0.0120)$ & $-0.0522^{* * *}$ & $(0.0177)$ \\
\hline part-time & -0.0473 & $(0.2656)$ & 0.1918 & $(0.3898)$ \\
\hline weekend-work (yes) & -0.0056 & $(0.0526)$ & 0.0114 & $(0.0639)$ \\
\hline weekend-work (no) & $-0.0520^{* * *}$ & $(0.0144)$ & $-0.0391^{*}$ & $(0.0221)$ \\
\hline firm size $(1-19)$ & -0.0437 & $(0.0384)$ & 0.0247 & $(0.0568)$ \\
\hline firm size $(20-49)$ & -0.0412 & $(0.0323)$ & -0.0063 & $(0.0391)$ \\
\hline firm size $(50-199)$ & $-0.0757^{* *}$ & $(0.0379)$ & -0.0030 & $(0.0541)$ \\
\hline firm size $(200-499)$ & NA & ( NA ) & NA & ( NA ) \\
\hline firm size $(500+)$ & NA & $(\mathrm{NA})$ & NA & $(\mathrm{NA})$ \\
\hline
\end{tabular}

Source: German Job Vacancy Survey 2014, restricted sample.

Robust standard errors in brackets. ${ }^{* * *}$ indicates $p<0.01$; ${ }^{* *} p<0.05$; $^{*} p<0.1$.

NA: The number of observations was too small. 
Table 14: Recruiting difficulties due to "high wage demands" for different subgroups

\begin{tabular}{|c|c|c|c|c|}
\hline & \multicolumn{4}{|c|}{ Recruiting difficulties due to "high wage demands" } \\
\hline & \multicolumn{2}{|c|}{ Marginal effects (probit) } & \multicolumn{2}{|c|}{ Marginal effects (probit) } \\
\hline & \multicolumn{2}{|c|}{ PEA search channel } & \multicolumn{2}{|c|}{ PEA hiring channel } \\
\hline & $(1)$ & $(2)$ & $(3)$ & $(4)$ \\
\hline & \multicolumn{4}{|c|}{ full sample } \\
\hline low qualification & $0.0982^{* * *}$ & $(0.0263)$ & $-0.0619^{*}$ & $(0.0317)$ \\
\hline medium qualification & $0.0417^{* * *}$ & $(0.0046)$ & -0.0067 & $(0.0053)$ \\
\hline high qualification & $0.0542 * * *$ & $(0.0110)$ & $-0.0482^{* * *}$ & $(0.0177)$ \\
\hline occupation specific exp. (yes) & $0.0366^{* * *}$ & $(0.0060)$ & -0.0095 & $(0.0073)$ \\
\hline occupation specific exp. (no) & $0.0483^{* * *}$ & $(0.0056)$ & $-0.0140^{* *}$ & $(0.0065)$ \\
\hline permanent & $0.0483^{* * *}$ & $(0.0057)$ & -0.0030 & $(0.0071)$ \\
\hline temporary & $0.0354^{* * *}$ & $(0.0058)$ & $-0.0172^{* *}$ & $(0.0068)$ \\
\hline full-time & $0.0387^{* * *}$ & $(0.0044)$ & $-0.0128^{* *}$ & $(0.0053)$ \\
\hline part-time & $0.0693^{* * *}$ & $(0.0122)$ & -0.0149 & $(0.0143)$ \\
\hline weekend-work (yes) & $0.0848 * * *$ & $(0.0138)$ & $-0.0585^{* * *}$ & $(0.0168)$ \\
\hline weekend-work (no) & $0.0343^{* * *}$ & $(0.0042)$ & -0.0062 & $(0.0049)$ \\
\hline firm size $(1-19)$ & $0.0839 * * *$ & $(0.0167)$ & -0.0059 & $(0.0173)$ \\
\hline firm size $(20-49)$ & $0.0527 * * *$ & $(0.0097)$ & $-0.0213^{*}$ & $(0.0116)$ \\
\hline firm size $(50-199)$ & $0.0369 * * *$ & $(0.0100)$ & -0.0119 & $(0.0123)$ \\
\hline firm size (200 - 499) & $0.0556^{* * *}$ & $(0.0232)$ & 0.0256 & $(0.0365)$ \\
\hline \multirow[t]{2}{*}{ firm size $(500+)$} & 0.0290 & $(0.0244)$ & -0.0575 & $(0.0481)$ \\
\hline & \multicolumn{4}{|c|}{ restricted sample } \\
\hline low qualification & $0.1768^{* * *}$ & $(0.0664)$ & $-0.2144^{* * *}$ & $(0.0729)$ \\
\hline medium qualification & $0.0407^{* * *}$ & $(0.0055)$ & $-0.0109^{*}$ & $(0.0064)$ \\
\hline high qualification & $0.0682^{* * *}$ & $(0.0228)$ & $-0.1191^{* * *}$ & $(0.0412)$ \\
\hline occupation specific exp. (yes) & $0.0403^{* * *}$ & $(0.0073)$ & $-0.0220^{* *}$ & $(0.0094)$ \\
\hline occupation specific exp. (no) & $0.0532^{* * *}$ & $(0.0078)$ & $-0.0182^{*}$ & $(0.0086)$ \\
\hline permanent & $0.0635^{* * *}$ & $(0.0081)$ & -0.0079 & $(0.0096)$ \\
\hline temporary & $0.0356^{* * *}$ & $(0.0080)$ & $-0.0310^{* * *}$ & $(0.0100)$ \\
\hline full-time & $0.0370^{* * *}$ & $(0.0052)$ & $-0.0150^{* *}$ & $(0.0063)$ \\
\hline part-time & $0.0830^{* * *}$ & $(0.0180)$ & $-0.0348^{*}$ & $(0.0196)$ \\
\hline weekend-work (yes) & $0.1122^{* * *}$ & $(0.0212)$ & $-0.1167^{* * *}$ & $(0.0270)$ \\
\hline weekend-work (no) & $0.0309 * * *$ & $(0.0051)$ & -0.0081 & $(0.0061)$ \\
\hline firm size $(1-19)$ & $0.0839 * * *$ & $(0.0167)$ & -0.0059 & $(0.0173)$ \\
\hline firm size $(20-49)$ & $0.0710^{* * *}$ & $(0.0160)$ & $-0.0691^{* * *}$ & $(0.0207)$ \\
\hline firm size $(50-199)$ & $0.0650 * * *$ & $(0.0152)$ & $-0.0522^{* * *}$ & $(0.0202)$ \\
\hline firm size $(200-499)$ & NA & NA & NA & NA \\
\hline firm size $(500+)$ & NA & NA & NA & NA \\
\hline
\end{tabular}

Source: German Job Vacancy Survey 2005-2010.

Robust standard errors in brackets. ${ }^{* * *}$ indicates $p<0.01$; ${ }^{*} p<0.05$; ${ }^{*} p<0.1$.

NA: The number of observations was too small. 
Table 15: Regressions to generate variables for Tables 8 and $\mathbf{1 7}$

\begin{tabular}{|c|c|c|c|c|}
\hline & \multicolumn{4}{|c|}{ OLS-Regressions: Number of applicants (log) } \\
\hline & \multicolumn{2}{|c|}{ full sample } & \multicolumn{2}{|c|}{ restricted sample } \\
\hline & $\begin{array}{c}\text { PEA } \\
(1)\end{array}$ & $\begin{array}{c}\text { private market } \\
\text { (2) }\end{array}$ & $\begin{array}{c}\text { PEA } \\
(3)\end{array}$ & $\begin{array}{c}\text { private market } \\
\text { (4) }\end{array}$ \\
\hline number of search channels & & $\begin{array}{c}0.4496 * * * \\
(0.0278)\end{array}$ & & $\begin{array}{c}0.4982^{* * *} \\
(0.0411)\end{array}$ \\
\hline number of search channels ${ }^{2}$ & & $\begin{array}{c}-0.0528 * * * \\
(0.0049)\end{array}$ & & $\begin{array}{c}-0.0650 * * * \\
(0.0079)\end{array}$ \\
\hline low qualification & $\begin{array}{c}0.0226 \\
(0.0592)\end{array}$ & $\begin{array}{c}-0.2104^{* * * *} \\
(0.0478)\end{array}$ & $\begin{array}{l}-0.0956 \\
(0.0813)\end{array}$ & $\begin{array}{c}-0.2276^{* * *} \\
(0.0615)\end{array}$ \\
\hline high qualification & $\begin{array}{c}-0.1339^{* *} \\
(0.0596)\end{array}$ & $\begin{array}{c}0.1170^{* * *} \\
(0.0392)\end{array}$ & $\begin{array}{l}-0.0555 \\
(0.0769)\end{array}$ & $\begin{array}{l}0.0957^{*} \\
(0.0499)\end{array}$ \\
\hline occupation specific experience & $\begin{array}{l}0.0168 \\
(0.0308)\end{array}$ & $\begin{array}{c}0.0899 * * * \\
(0.0229)\end{array}$ & $\begin{array}{c}0.0395 \\
(0.0416)\end{array}$ & $\begin{array}{c}0.0811^{* * *} \\
(0.0293)\end{array}$ \\
\hline permanent & $\begin{array}{c}0.0340 \\
(0.0317)\end{array}$ & $\begin{array}{c}0.2095^{* * *} \\
(0.0239)\end{array}$ & $\begin{array}{c}0.0479 \\
(0.0444)\end{array}$ & $\begin{array}{c}0.2314^{* * *} \\
(0.0310)\end{array}$ \\
\hline full-time & $\begin{array}{c}0.1617^{* * *} \\
(0.0417)\end{array}$ & $\begin{array}{c}0.0228 \\
(0.0340)\end{array}$ & $\begin{array}{c}0.1233^{* *} \\
(0.0533)\end{array}$ & $\begin{array}{l}-0.0062 \\
(0.0419)\end{array}$ \\
\hline weekend-work & $\begin{array}{c}0.0461 \\
(0.0481)\end{array}$ & $\begin{array}{c}0.0579 \\
(0.0368)\end{array}$ & $\begin{array}{c}0.0523 \\
(0.0665)\end{array}$ & $\begin{array}{c}0.0697 \\
(0.0460)\end{array}$ \\
\hline firm size (log) & $\begin{array}{c}-0.0343^{* * *} \\
(0.0114)\end{array}$ & $\begin{array}{c}0.0987^{* * *} * \\
(0.0086)\end{array}$ & $\begin{array}{l}-0.0121 \\
(0.0153)\end{array}$ & $\begin{array}{c}0.0960^{* * *} \\
(0.0110)\end{array}$ \\
\hline "financial constraints" & $\begin{array}{c}0.0701 \\
(0.0497)\end{array}$ & $\begin{array}{c}-0.1434^{* * *} \\
(0.0427)\end{array}$ & $\begin{array}{c}0.0577 \\
(0.0680)\end{array}$ & $\begin{array}{c}-0.1367^{* *} \\
(0.0563)\end{array}$ \\
\hline "low sales" & $\begin{array}{l}-0.0062 \\
(0.0411)\end{array}$ & $\begin{array}{c}-0.0926 * * * \\
(0.0321)\end{array}$ & $\begin{array}{c}0.0760 \\
(0.0585)\end{array}$ & $\begin{array}{c}-0.1363^{* * *} \\
(0.0430)\end{array}$ \\
\hline "not enough suitable employees" & $\begin{array}{c}-0.0999^{* *} \\
(0.0476)\end{array}$ & $\begin{array}{c}-0.1370^{* * *} \\
(0.0382)\end{array}$ & $\begin{array}{l}0.1250^{*} \\
(0.0759)\end{array}$ & $\begin{array}{c}-0.1070^{*} \\
(0.0573)\end{array}$ \\
\hline $\begin{array}{l}\text { year-, region-, industry-FE } \\
\text { (year x region)-FE }\end{array}$ & $\begin{array}{l}\text { yes } \\
\text { yes }\end{array}$ & $\begin{array}{l}\text { yes } \\
\text { yes }\end{array}$ & $\begin{array}{l}\text { yes } \\
\text { yes }\end{array}$ & $\begin{array}{l}\text { yes } \\
\text { yes }\end{array}$ \\
\hline Peudo-R ${ }^{2}$ & 0.1718 & 0.2512 & 0.2031 & 0.2553 \\
\hline $\mathrm{N}$ & 4,705 & 10,734 & 2,694 & 6,869 \\
\hline
\end{tabular}

Source: German Job Vacancy Survey 2005-2008. Since we consider in columns (2) and (4) only applicants from the private market, we deduct the 1 from the number of search channels in case the firm is registered with the PEA Robust standard errors in brackets. *** indicates $p<0.01{ }^{* *} p<0.05{ }^{*} p<0.1$ 
Table 16: Regressions to generate variables for Tables 8 and 17

\begin{tabular}{|c|c|c|c|c|}
\hline & \multicolumn{4}{|c|}{ OLS-Regressions: Number of suitable applicants (log) } \\
\hline & $\begin{array}{l}\text { PEA } \\
(1)\end{array}$ & $\begin{array}{c}\text { private market } \\
\text { (2) }\end{array}$ & $\begin{array}{c}\text { PEA } \\
(3)\end{array}$ & $\begin{array}{c}\text { private market } \\
\text { (4) }\end{array}$ \\
\hline number of applicants (log) & $\begin{array}{c}0.4735^{* * * *} \\
(0.0120)\end{array}$ & $\begin{array}{c}0.5516^{* * * *} \\
(0.0052)\end{array}$ & $\begin{array}{c}0.5040^{* * * *} \\
(0.0179)\end{array}$ & $\begin{array}{c}0.5717^{* * * *} \\
(0.0064)\end{array}$ \\
\hline low qualification & $\begin{array}{l}0.0593^{*} \\
(0.0361)\end{array}$ & $\begin{array}{l}-0.0149 \\
(0.0211)\end{array}$ & $\begin{array}{c}0.0694 \\
(0.0462)\end{array}$ & $\begin{array}{l}-0.0156 \\
(0.0271)\end{array}$ \\
\hline high qualification & $\begin{array}{l}-0.0387 \\
(0.0346)\end{array}$ & $\begin{array}{c}0.0145 \\
(0.0176)\end{array}$ & $\begin{array}{c}0.0308 \\
(0.0469)\end{array}$ & $\begin{array}{c}0.0163 \\
(0.0220)\end{array}$ \\
\hline occupation specific experience & $\begin{array}{l}-0.0305 \\
(0.0191)\end{array}$ & $\begin{array}{c}-0.0664^{* * *} \\
(0.0104)\end{array}$ & $\begin{array}{c}-0.0589^{* *} \\
(0.0258)\end{array}$ & $\begin{array}{c}-0.0602^{* * *} \\
(0.0131)\end{array}$ \\
\hline permanent & $\begin{array}{c}-0.0764^{* * *} \\
(0.0197)\end{array}$ & $\begin{array}{c}-0.0051 \\
(0.0109)\end{array}$ & $\begin{array}{c}-0.0905^{* * *} \\
(0.0279)\end{array}$ & $\begin{array}{c}-0.0114 \\
(0.0138)\end{array}$ \\
\hline full-time & $\begin{array}{c}-0.0176 \\
(0.0257)\end{array}$ & $\begin{array}{c}-0.0430 * * * \\
(0.0147)\end{array}$ & $\begin{array}{c}-0.0301 \\
(0.0341)\end{array}$ & $\begin{array}{l}-0.0264 \\
(0.0179)\end{array}$ \\
\hline weekend-work & $\begin{array}{c}-0.0079 \\
(0.0307)\end{array}$ & $\begin{array}{c}0.0102 \\
(0.0167)\end{array}$ & $\begin{array}{l}-0.0277 \\
(0.0392)\end{array}$ & $\begin{array}{c}0.0170 \\
(0.0203)\end{array}$ \\
\hline firm size (log) & $\begin{array}{c}0.0284^{* * *} \\
(0.0069)\end{array}$ & $\begin{array}{c}0.0238^{* * *} * \\
(0.0039)\end{array}$ & $\begin{array}{c}0.0249^{* *} \\
(0.0098)\end{array}$ & $\begin{array}{c}0.0227^{* * *} \\
(0.0048)\end{array}$ \\
\hline "financial constraints" & $\begin{array}{l}-0.0049 \\
(0.0312)\end{array}$ & $\begin{array}{c}0.0028 \\
(0.0197)\end{array}$ & $\begin{array}{l}-0.0481 \\
(0.0424)\end{array}$ & $\begin{array}{l}-0.0121 \\
(0.0252)\end{array}$ \\
\hline "low sales" & $\begin{array}{c}0.0263 \\
(0.0260)\end{array}$ & $\begin{array}{c}0.0100 \\
(0.0146)\end{array}$ & $\begin{array}{c}0.0179 \\
(0.0376)\end{array}$ & $\begin{array}{c}0.0099 \\
(0.0186)\end{array}$ \\
\hline "not enough suitable employees" & $\begin{array}{c}-0.1852^{* * *} \\
(0.0287)\end{array}$ & $\begin{array}{c}-0.1430 * * * \\
(0.0183)\end{array}$ & $\begin{array}{c}-0.1936^{* * *} \\
(0.0484)\end{array}$ & $\begin{array}{c}-0.1253^{* * *} \\
(0.0272)\end{array}$ \\
\hline $\begin{array}{l}\text { year-, region-, industry-FE } \\
\text { (year x region)-FE }\end{array}$ & $\begin{array}{l}\text { yes } \\
\text { yes }\end{array}$ & $\begin{array}{l}\text { yes } \\
\text { yes }\end{array}$ & $\begin{array}{l}\text { yes } \\
\text { yes }\end{array}$ & $\begin{array}{l}\text { yes } \\
\text { yes }\end{array}$ \\
\hline Peudo- $\mathrm{R}^{2}$ & 0.5072 & 0.6885 & 0.5573 & 0.7125 \\
\hline $\mathrm{N}$ & 4,457 & 10,294 & 2,557 & 6,624 \\
\hline
\end{tabular}

Source: German Job Vacancy Survey 2005-2008.

Robust standard errors in brackets. $* * *$ indicates $p<0.01$; ** $p<0.05$; ${ }^{*} p<0.1$. 
Table 17: Comparative statics for different subgroups: PEA used as search channel

\begin{tabular}{|c|c|c|c|c|}
\hline & \multicolumn{4}{|c|}{ Ordered-Probit-Regressions: Marginal Effects } \\
\hline & \multicolumn{2}{|c|}{ private market } & \multicolumn{2}{|c|}{ PEA } \\
\hline & $\begin{array}{c}\text { exp. n. of } \\
\text { appl. (log) } \\
\text { (1) }\end{array}$ & $\begin{array}{l}\text { exp. frac. of } \\
\text { suit. appl. } \\
\text { (2) }\end{array}$ & $\begin{array}{c}\text { exp. n. of } \\
\text { appl. (log) } \\
\text { (3) }\end{array}$ & $\begin{array}{c}\text { exp. frac. of } \\
\text { suit. appl. } \\
\text { (4) }\end{array}$ \\
\hline & \multicolumn{4}{|c|}{ full sample } \\
\hline low qualification & $\begin{array}{c}-0.4115^{* * *} \\
(0.0580)\end{array}$ & $\begin{array}{c}-0.7753^{* * *} \\
(0.0542)\end{array}$ & $\begin{array}{c}0.2743^{* *} \\
(0.1086)\end{array}$ & $\begin{array}{c}0.1655 \\
(0.1273)\end{array}$ \\
\hline medium qualification & $\begin{array}{c}-0.1267^{* * *} \\
(0.0210)\end{array}$ & $\begin{array}{c}-0.4992^{* * *} \\
(0.0204)\end{array}$ & $\begin{array}{c}0.1378^{* * *} \\
(0.0374)\end{array}$ & $\begin{array}{c}0.3893^{* * *} \\
(0.0466)\end{array}$ \\
\hline high qualification & $\begin{array}{c}-0.0115 \\
(0.0407)\end{array}$ & $\begin{array}{c}-0.1780^{* * *} \\
(0.0427)\end{array}$ & $\begin{array}{c}0.1359^{* *} \\
(0.0605)\end{array}$ & $\begin{array}{c}0.3427^{* * *} \\
(0.0798)\end{array}$ \\
\hline occupation specific exp. (yes) & $\begin{array}{c}-0.0968^{* * *} * \\
(0.0258)\end{array}$ & $\begin{array}{c}-0.4336^{* * *} \\
(0.0259)\end{array}$ & $\begin{array}{c}0.1612^{* * *} \\
(0.0438)\end{array}$ & $\begin{array}{c}0.3986^{* * *} \\
(0.0565)\end{array}$ \\
\hline occupation specific exp. (no) & $\begin{array}{c}-0.1670^{* * *} \\
(0.0243)\end{array}$ & $\begin{array}{c}-0.4800^{* * *} \\
(0.0235)\end{array}$ & $\begin{array}{c}0.1299 * * * \\
(0.0441)\end{array}$ & $\begin{array}{c}0.3196^{* * *} \\
(0.0534)\end{array}$ \\
\hline permanent & $\begin{array}{c}-0.0669^{* * *} \\
(0.0257)\end{array}$ & $\begin{array}{c}-0.3551^{* * *} \\
(0.0263)\end{array}$ & $\begin{array}{c}0.1469^{* * *} \\
(0.0424)\end{array}$ & $\begin{array}{c}0.4110^{* * *} \\
(0.0556)\end{array}$ \\
\hline temporary & $\begin{array}{c}-0.1839 * * * \\
(0.0243)\end{array}$ & $\begin{array}{c}-0.5359 * * * \\
(0.0235)\end{array}$ & $\begin{array}{c}0.1579 * * * \\
(0.0458)\end{array}$ & $\begin{array}{c}0.3288^{* * *} \\
(0.0539)\end{array}$ \\
\hline full-time & $\begin{array}{c}-0.1172^{* * *} \\
(0.0195)\end{array}$ & $\begin{array}{c}-0.4497^{* * *} \\
(0.0198)\end{array}$ & $\begin{array}{c}0.1601^{* * *} \\
(0.0334)\end{array}$ & $\begin{array}{c}0.3558^{* * *} \\
(0.0424)\end{array}$ \\
\hline part-time & $\begin{array}{c}-0.2198 * * * \\
(0.0411)\end{array}$ & $\begin{array}{c}-0.5157^{* * *} \\
(0.0371)\end{array}$ & $\begin{array}{c}0.0877 \\
(0.0864)\end{array}$ & $\begin{array}{c}0.3944^{* * *} \\
(0.0889)\end{array}$ \\
\hline weekend-work (yes) & $\begin{array}{c}0.0014 \\
(0.0469)\end{array}$ & $\begin{array}{c}-0.5490^{* * *} \\
(0.0447)\end{array}$ & $\begin{array}{c}0.0020 \\
(0.0839)\end{array}$ & $\begin{array}{c}0.3562^{* * *} \\
(0.0998)\end{array}$ \\
\hline \multirow[t]{2}{*}{ weekend-work (no) } & $\begin{array}{c}-0.1613^{* * *} \\
(0.0190)\end{array}$ & $\begin{array}{c}-0.4395^{* * *} \\
(0.0190)\end{array}$ & $\begin{array}{c}0.1587^{* * *} \\
(0.0332)\end{array}$ & $\begin{array}{c}0.3600^{* * *} \\
(0.0420)\end{array}$ \\
\hline & \multicolumn{4}{|c|}{ restricted sample } \\
\hline low qualification & $\begin{array}{c}-0.4665^{* * *} \\
(0.0734)\end{array}$ & $\begin{array}{c}-0.8188^{* * *} \\
(0.0720)\end{array}$ & $\begin{array}{c}0.2326^{* *} \\
(0.1034)\end{array}$ & $\begin{array}{l}-0.0567 \\
(0.1394)\end{array}$ \\
\hline medium qualification & $\begin{array}{c}-0.1695^{* * *} \\
(0.0245)\end{array}$ & $\begin{array}{c}-0.4535^{* * *} \\
(0.0243)\end{array}$ & $\begin{array}{c}0.1081^{* * * *} \\
(0.0354)\end{array}$ & $\begin{array}{c}0.3352^{* * *} \\
(0.0547)\end{array}$ \\
\hline high qualification & $\begin{array}{c}-0.0753 \\
(0.0476)\end{array}$ & $\begin{array}{c}-0.1606^{* * *} \\
(0.0507)\end{array}$ & $\begin{array}{l}0.1145^{*} \\
(0.0638)\end{array}$ & $\begin{array}{c}0.2969 * * * \\
(0.0984)\end{array}$ \\
\hline occupation specific exp. (yes) & $\begin{array}{c}-0.1607^{* * *} * \\
(0.0303)\end{array}$ & $\begin{array}{c}-0.3637^{* * *} \\
(0.0310)\end{array}$ & $\begin{array}{c}0.1479^{* * * *} \\
(0.0427)\end{array}$ & $\begin{array}{c}0.3427^{* * * *} \\
(0.0668)\end{array}$ \\
\hline occupation specific exp. (no) & $\begin{array}{c}-0.2082^{* * *} \\
(0.0279)\end{array}$ & $\begin{array}{c}-0.4642^{* * *} \\
(0.0280)\end{array}$ & $\begin{array}{c}0.0838^{* *} \\
(0.4157)\end{array}$ & $\begin{array}{c}0.2698^{* * *} \\
(0.0624)\end{array}$ \\
\hline permanent & $\begin{array}{c}-0.1102^{* * *} \\
(0.0314)\end{array}$ & $\begin{array}{c}-0.3170^{* * *} \\
(0.0327)\end{array}$ & $\begin{array}{c}0.1081^{* * * *} \\
(0.0410)\end{array}$ & $\begin{array}{c}0.3195^{* * *} \\
(0.0675)\end{array}$ \\
\hline temporary & $\begin{array}{c}-0.2431^{* * *} \\
(0.0280)\end{array}$ & $\begin{array}{c}-0.4863^{* * *} \\
(0.0279)\end{array}$ & $\begin{array}{c}0.1126^{* * *} \\
(0.0429)\end{array}$ & $\begin{array}{c}0.2871^{* * *} \\
(0.0629)\end{array}$ \\
\hline full-time & $\begin{array}{c}-0.1691^{* * *} \\
(0.0231)\end{array}$ & $\begin{array}{c}-0.4100^{* * *} \\
(0.0238)\end{array}$ & $\begin{array}{c}0.1133^{* * * *} \\
(0.0323)\end{array}$ & $\begin{array}{c}0.2850^{* * *} \\
(0.0511)\end{array}$ \\
\hline part-time & $\begin{array}{c}-0.2429 * * * \\
(0.0472)\end{array}$ & $\begin{array}{c}-0.4622^{* * *} \\
(0.0451)\end{array}$ & $\begin{array}{c}0.0678 \\
(0.0726)\end{array}$ & $\begin{array}{c}0.3348^{* * *} \\
(0.1014)\end{array}$ \\
\hline weekend-work (yes) & $\begin{array}{c}-0.0654 \\
(0.0574)\end{array}$ & $\begin{array}{c}-0.5313^{* * *} \\
(0.0570)\end{array}$ & $\begin{array}{c}0.0685 \\
(0.0827)\end{array}$ & $\begin{array}{c}0.3295^{* * *} \\
(0.1174)\end{array}$ \\
\hline weekend-work (no) & $\begin{array}{c}-0.2167^{* * *} \\
(0.0221)\end{array}$ & $\begin{array}{c}-0.4032^{* * *} \\
(0.0226)\end{array}$ & $\begin{array}{c}0.1155^{* * *} \\
(0.0318)\end{array}$ & $\begin{array}{c}0.2821^{* * *} \\
(0.0496)\end{array}$ \\
\hline
\end{tabular}

Source: German Job Vacancy Survey 2005-2008.

Robust standard errors in brackets. *** indicates $p<0.01 ;{ }^{* *} p<0.05 ;{ }^{*} p<0.1$.

The number of observations was too small to obtain results for different firm sizes. 